Article

\title{
Inter-Metropolitan Land-Price Characteristics and Patterns in the Beijing-Tianjin-Hebei Urban Agglomeration in China
}

\author{
Can $\mathrm{Li}^{1,2}{ }^{1}$, Yu Meng ${ }^{1}$, Yingkui $\mathrm{Li}^{3}{ }^{1}$, Jingfeng $\mathrm{Ge}^{1,2, *}$ and Chaoran Zhao ${ }^{1}$ \\ 1 College of Resource and Environmental Science, Hebei Normal University, Shijiazhuang 050024, China \\ 2 Hebei Key Laboratory of Environmental Change and Ecological Construction, Shijiazhuang 050024, China \\ 3 Department of Geography, The University of Tennessee, Knoxville, TN 37996, USA \\ * Correspondence: gejingfeng@hebtu.edu.cn; Tel.: +86-0311-8078-7636
}

Received: 8 July 2019; Accepted: 25 August 2019; Published: 29 August 2019

check for updates

\begin{abstract}
The continuous expansion of urban areas in China has increased cohesion and synergy among cities. As a result, the land price in an urban area is not only affected by the city's own factors, but also by its interaction with nearby cities. Understanding the characteristics, types, and patterns of urban interaction is of critical importance in regulating the land market and promoting coordinated regional development. In this study, we integrated a gravity model with an improved Voronoi diagram model to investigate the gravitational characteristics, types of action, gravitational patterns, and problems of land market development in the Beijing-Tianjin-Hebei urban agglomeration region based on social, economic, transportation, and comprehensive land-price data from 2017. The results showed that the gravitational value of land prices for Beijing, Tianjin, Langfang, and Tangshan cities (11.24-63.35) is significantly higher than that for other cities (0-6.09). The gravitational structures are closely connected for cities around Beijing and Tianjin, but loosely connected for peripheral cities. Further, various types of radiation, conduction, and convection actions exist in relation to urban land prices. In terms of gravitational patterns, the range of influence of land prices is not limited to the administrative boundaries of each city. Five clusters of urban land prices can be identified based on the gravitational structure. The land-price gravity value of the city cluster around Beijing accounted for $66.4 \%$ of the total. The polarizing effect of land-price levels and influence is clearly evident in Beijing and Tianjin, while a lock-in effect is evident in Xingtai and Handan in the south of the region.
\end{abstract}

Keywords: city land price; gravitational model; Voronoi diagram model; gravitational pattern; Beijing-Tianjin-Hebei urban agglomeration in China

\section{Introduction}

The rapid expansion of urban areas in China has attracted worldwide attention in recent years [1-4]. However, rapid urbanization and economic development have also created numerous problems, such as widespread disease in urban areas and a large gap in development between regional and urban areas. Different development stages and levels exist as a result of unreasonable regional industrial structures and market mechanisms, variations in development policies, and inefficient resource allocation $[5,6]$. Thus, the coordinated development of regions and cities has become an important aspect of social and economic development and reform in China [7]. The Beijing-Tianjin-Hebei region is home to a large population and a high concentration of industrial clusters, and offers many political, resource, human talent, and technological advantages. However, the coordinated development of the region is still in its initial stages, with poor inter-metropolitan economic cooperation, weak complementarity in terms of industrial structure and resource management, and imbalanced development. To promote 
the coordinated development of the Beijing-Tianjin-Hebei region, in 2015, the Chinese government promulgated the "Outline of Beijing-Tianjin-Hebei Cooperative Development Planning" and proposed the task of Beijing's industrial transfer to surrounding cities. However, in the process of implementation, different traditional concepts of local governments, such as different land policy orientations and local protection policies, meant that the coordinated development of Beijing, Tianjin, and Hebei did not proceed smoothly. In 2017, Tianjin had set up 12 undertaking platforms for industries transferred from Beijing, occupying an area of $355.78 \mathrm{~km}^{2}$, but only $47 \%$ of this area complied with local land planning regulations. Meanwhile, more than 200 undertaking platforms were set up in Hebei Province. The planned area of land occupied by these platforms was $19,500 \mathrm{~km}^{2}$, which exceeded the total area under Beijing's jurisdiction by $16,400 \mathrm{~km}^{2}$, far exceeding the actual demand for land. Major differences continued to exist in relation to the industrial planning, land planning, and land supply policies of the Beijing, Tianjin, and Hebei regions. The government failed to analyze the characteristics of and interrelationships among the various urban land markets, resulting in inconsistent industrial transfer and land-use plans. Land-use efficiency was poor, output was low, and there was significant waste. In recent years, numerous scholars have analyzed the differences in regional economic development, production structures, regional population structures, urban land-use changes, urban ecological and environmental changes, and landscape patterns [8-11]. However, there have been few studies on the urban land market in the Beijing-Tianjin-Hebei region, especially in relation to the differences in land prices. Reasonable use of land resources is the key to promoting industrial transfer from Beijing to Tianjin and, thus, the following questions need to be answered: What is the relationship between land resource elements in the Beijing-Tianjin-Hebei urban agglomeration? How should the development of an inter-city land market be coordinated? Land price is an important economic lever in regulating the land market. Identifying the interactions between urban land prices and the gravitational patterns of land prices, and exploring the path of regional land market integration are useful for answering the above questions and achieving the coordinated development of industrial land use.

The optimal allocation of land resources plays a key role in the sustainable development of a region, and is closely related to the scale of urban expansion, environmental protection, and the optimization of population and industrial structures. As an important means of adjusting the land market and optimizing land resources, the land price has become a key indicator of urban functionality and industrial guidance, directly affecting people's choice and consumption of land resources. The differences in land prices among various regions and cities are related to morphological development and changing trends in land use that reflect the heterogeneity of cities in the region. To date, most studies on land prices have focused on influencing factors, spatiotemporal changes, and the relationships with urbanization and industrial and economic development, while studies on the factors influencing land prices have mainly focused on discrimination and quantification. For example, some studies have classified the influencing factors from the perspectives of supply and demand [12], or at the macro and micro levels [13], while others have identified the key factors affecting land prices using specific indicators of various factors in various models [14-17]. Some studies have investigated the mechanism underlying the effect of a specific factor, such as population structure and distribution [18], the regional environment [19,20], urban traffic conditions [21-23], and national land policy [24-27], on land prices. Hedonic price models have played an important role in the study of factors influencing land prices. Ridker was the first to apply hedonic price theory to the analysis of the housing market using a hedonic price model to study the impact of the improvement of the living environment on housing prices [28]. Since then, the hedonic price model had gradually developed into one of the most widely used models in the field of real-estate prices. It is widely accepted that differences in the characteristics of real estate are reflected in real-estate prices [29]. Thus, the hedonic price model has been widely used in analyses of factors influencing land and house prices. In micro-research, scholars have applied hedonic price theory to construct house price characteristic variables including house location, environmental quality, population density, and house size [30], estimated the importance of amenities and productive land characteristics [31] and transportation convenience [32] in relation to 
land prices, and analyzed the effects of environmental factors (e.g., window orientation, green-space view, floor height, and building location) [33], environmental amenities [34,35], and public facilities (e.g., the public transport system and the central business district) [36] that have significant effects on housing prices. In terms of macro-level research, scholars have established a variety of characteristic variables that help to explain land prices, such as the Luxembourg urban land-price characteristics variables (including accessibility, proximity, legal, social, and economic aspects) [37], China's urban comprehensive land-price characteristics (land supply and demand, economic and social levels, and policies) [38], and China's urban residential land-price characteristics (urban location, development potential, and socioeconomic level) [39]. In previous studies, land-price variables have included population, the environment, transportation, and social, economic, and policy factors, which provide a reference point for the construction of the urban residential land-price factors used in this study. Numerous studies have focused on the improvement of methods and models used to identify spatial and temporal patterns in land prices, such as the application and improvement of spatial autocorrelation, spatial measurement, big data analysis, and multifractal models. These improved methods and models have been successfully applied to the analysis of temporal changes, spatial distributions, and spatial patterns in urban land prices [40-46]. In recent years, the rapid development of China's economy has led to soaring land and housing prices, and numerous studies have focused on the question of whether the relationship between land prices and housing prices is reasonable [47-49]. Some scholars have examined the relationships between land prices and industrial layout [50], urban spatial structure [51], land-use efficiency [52], and macroeconomic fluctuations [53], and evaluated the current land-use policy [54-57] with a view to optimizing the land-management system and creating a healthy land market in China. The abovementioned studies have played a positive role in promoting China's land market and the formulation of land-use policies. However, most of the studies on the factors influencing urban land prices have only focused on the analysis of either one or just a few variables, and there have been few studies aimed at building a comprehensive model of factors influencing land prices in urban agglomerations. Faced with the complex urbanization process taking place in China, in particular the coordinated development of the Beijing-Tianjin-Hebei urban agglomeration, it is necessary to construct a comprehensive set of variables that can explain the land-price characteristics of urban agglomerations. Further, most urban land-price studies have not considered the impact of gravitational intensity, land type, and spatial characteristics on land prices and the development of the land market.

The gravitational model, which originated in the field of physics, has been introduced to studies in the fields of urban geography and regional economics and gradually expanded to enable the analysis of spatial interactions among different regions [58]. In the 1930s, Reilly first applied the gravitational model to exploring retail relationships [59]. Later, Zipf used the gravitational model to establish the theoretical basis of spatial interactions among urban systems [60]. The gravitational model has also been used in relation to urban planning, transportation planning, trade relations, and tourism development. For example, Gulenada analyzed the relationship between the planning and construction of urban sub-centers and the structure of urban functional areas using the gravitational model [61], while Matsumoto used GDP, population, and Euclidean distance to measure the intensity of air traffic and analyze the network characteristics of international airports in metropolitan areas [62]. Fotheringham determined the location of the boundary between Dallas and Oklahoma City using the breaking-point method, and proposed a new route based on air passenger interactions using an improved gravitational model [63]. Celik studied changes in commodity flows among 48 states in the United States using spatial interaction modeling and identified the main factors influencing commodity flows [64]. Djankov investigated trade flow patterns among different regions and countries [65], Wolfe analyzed local tourism flows in Ottawa using the gravitational model with a modified distance function, and Russon studied the relationship between passenger flows, travel distance, and population density using an improved gravitational model [66]. In recent years, the gravitational model has also been applied to the analysis of urban expansion and land-use changes $[67,68]$, the simulation of regional 
population activities and urban landscapes [69,70], and the analysis of technological and economic factors influencing coordinated regional development [71]. The gravity model has also been applied to the study of economic relationships between cities and interactions among urban land prices. In studies of inter-urban economic relationships, scholars have analyzed the economic connection strength and spatial structure of the Wuhan metropolitan area [72], the Anhui Province urban agglomeration [73], urban agglomerations in the middle reaches of the Yangtze River [74], and the Beijing-Tianjin-Hebei urban agglomeration [75]. In studies of urban land prices, scholars have used the gravity model to establish a new method of urban land-price correction and balance [76,77], and have calculated the gravitational relationship among land prices in the Beijing-Tianjin-Hebei metropolitan area [78] and among 105 cities in China [79]. The Voronoi map was first proposed by Boregfore in 1986, and in recent years it has often been used to divide urban economic impact areas. Scholars have used Voronoi maps to divide the economic impact areas of 30 cities in Central China [80], Shiyan City in Hubei Province [81,82], and Tianshui City in Gansu Province [83]. In previous studies, the inter-city accessibility parameters used in the gravity model were often spatial distances. However, because of the differences in traffic conditions and modes of transportation between cities, accessibility and spatial distances between cities differ. Therefore, in this study, we develop a gravity model of urban land prices by calculating the actual distance between cities based on commonly used rail and road transport modes, and passenger and freight volumes between Beijing, Tianjin, and Hebei cities. Although the Voronoi diagram method can delineate the scope of urban influence, it cannot measure the intensity of interactions between cities. If the gravity model and the Voronoi diagram method are used together, the gravitational intensity between cities, the scope of urban influence, and the laws of gravitational differentiation among cities can be revealed simultaneously, providing a clearer analysis of the spatial patterns of interactions among cities. This study combines the two models in an attempt to explore the intensity, structure, and extent of geological attractions between cities. In summary, the gravitational model has become an important tool for studying regional spatial interactions. The essence of urban regionalization is the integration of city and regional economies, and the interactions between a city and its surrounding region provide the power necessary to achieve the coordinated development of the city and the region. Regional and urban factors are closely linked, and land prices are not only determined by direct factors, but also by the interactions between adjacent cities. The gravity of urban land prices shows the internal connection of urban land values, and reveals the degree of interaction of land capital, land supply and demand, and land policy among cities. Against the background of the coordinated development strategy relating to Beijing, Tianjin, and Hebei in China, it can be seen that adjacent cities are not merely viewed as independent entities, but are seen in the context of the interactions that occur among them. This is important in relation to coordinating the relationship between land resource allocation and regional economic development, and promoting interactions between cities and regions, thereby realizing complementary advantages.

In this study, based on the success of previous scholars in studying urban gravity and its range of influence, we investigate the gravitational characteristics of inter-city land prices, divide the urban land-price function into various types, and analyze the roles of different urban land values in the development of the regional land market in the Beijing-Tianjin-Hebei urban agglomeration. We also delineate the spatial patterns of regional land-price gravity and identify its spatial effects. The goal of this study is to provide support for decision-making in relation to the balanced development of the land market in the Beijing-Tianjin-Hebei urban agglomeration.

\section{Research Area}

The Beijing-Tianjin-Hebei region is the economic center of northern China, and includes the two municipalities of Beijing and Tianjin, and 11 cities in Hebei Province, including Shijiazhuang, Tangshan, Baoding, Langfang, Qinhuangdao, Zhangjiakou, Chengde, Cangzhou, Hengshui, Xingtai, and Handan (see Figure 1). It covers an area of $218,000 \mathrm{~km}^{2}$, accounting for $2.3 \%$ of China's total land area. 


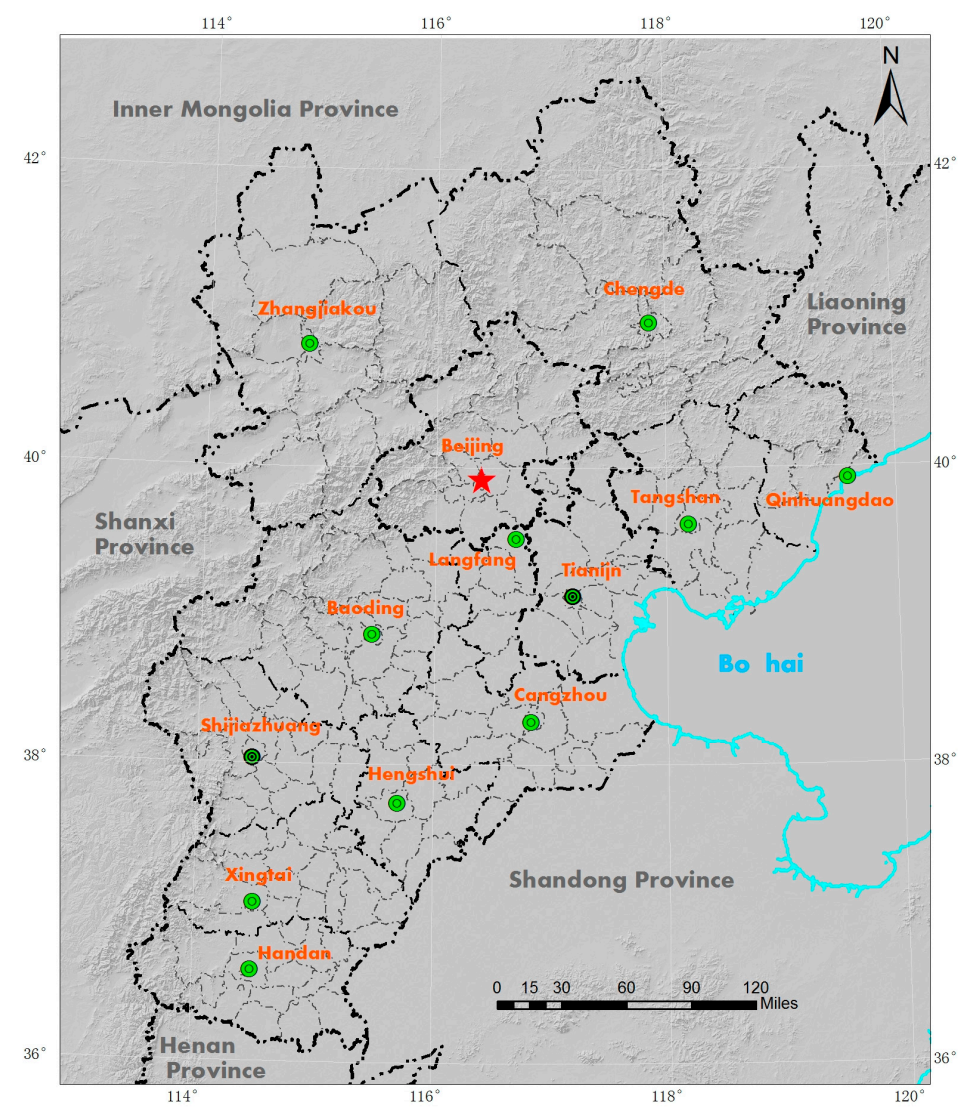

Figure 1. Research area.

In 2017, average per capita GDP in Beijing and Tianjin was 129,000 yuan and 119,000 yuan, respectively, which was higher than the average of 45,000 yuan in Hebei Province. The population distribution pattern showed a sparse population in the mountainous northern areas and a high population density in the central and southern plains. In particular, the population was highly concentrated in Beijing and Tianjin. The population densities in these two cities (1323 and 1315 people per $\mathrm{km}^{2}$, respectively) were more than three times the population density in Hebei Province (396 people per $\mathrm{km}^{2}$ ). These differences in economic activity and population density led to an imbalance in terms of urban land prices among these areas. The average land price in 2017 in Beijing, Tianjin, and Hebei Provinces were 38,673 yuan, 7007 yuan, and 2526 yuan per $\mathrm{m}^{2}$, respectively. That is, the average land price in Beijing was more than 15 times that in Hebei Province. The governments in the Beijing-Tianjin-Hebei urban agglomeration have built a comprehensive transportation system, including railways, highways, ports, and airports, and have basically adopted a radial network pattern centered on Beijing. In 2017, the regional railways extended over $9600 \mathrm{~km}$, while there was $8445 \mathrm{~km}$ of expressways. Travel distance, passenger volumes, and freight volumes can objectively reflect the degree of interaction between cities. In terms of travel distance, Beijing and Tianjin were $2931 \mathrm{~km}$ and $3021 \mathrm{~km}$, respectively, from other urban centers, with good traffic accessibility. Langfang and Baoding were $2936 \mathrm{~km}$ and $2984 \mathrm{~km}$, respectively, from other cities, and their traffic accessibility was comparable to that of Beijing and Tianjin. The accessibility of other urban centers was relatively weak (distances between cities were more than $3200 \mathrm{~km}$ ). In terms of external relationships, the number of passengers in Beijing, Tianjin, and Hebei were 675, 192, and 480 million people, respectively, and the freight volume was 239, 530, and 250 million tons, respectively. In Hebei Province, Baoding, Handan, Cangzhou, and Shijiazhuang had relatively strong talent exchanges, with passenger numbers of 70, 55, 48 , and 40 million people, respectively, which were clearly higher than those in other cities (all below 30 million people). Shijiazhuang and Tangshan had relatively strong economic exchanges, with freight 
volumes of 460 and 410 million tons, respectively, which were significantly higher than those of other cities (no more than 240 million tons). Thus, it can be seen that the degree of interconnection between cities was not solely related to travel distance, and the closely related cities were mostly distributed around Beijing and Tianjin. Supported by this transport system, which is gradually being improved, the Beijing-Tianjin-Hebei urban agglomeration is becoming increasingly connected in terms of economic ties, and is undergoing rapid coordinated development.

\section{Materials and Methods}

In this study, we used a gravitational model combined with a Voronoi diagram model based on breaking-point theory (see Figure 2). The gravitational model is used to measure and analyze the gravitational intensity, spatial characteristics, and types of land-price interactions between cities. The Voronoi diagram model is used to identify the gravitational pattern of urban land prices and analyze the spatial effects of urban land-price development. The gravitational model includes two parameters: the quality of the urban land price and the distance between two cities. The quality of the urban land price is based on the land price and its related socioeconomic indicators. The distance between two cities is based on traffic data including the lengths of inter-city railways and highways and passenger and freight volumes. The Voronoi diagram model uses the quality of urban land prices and the distance between cities to identify gravitational patterns in land prices.

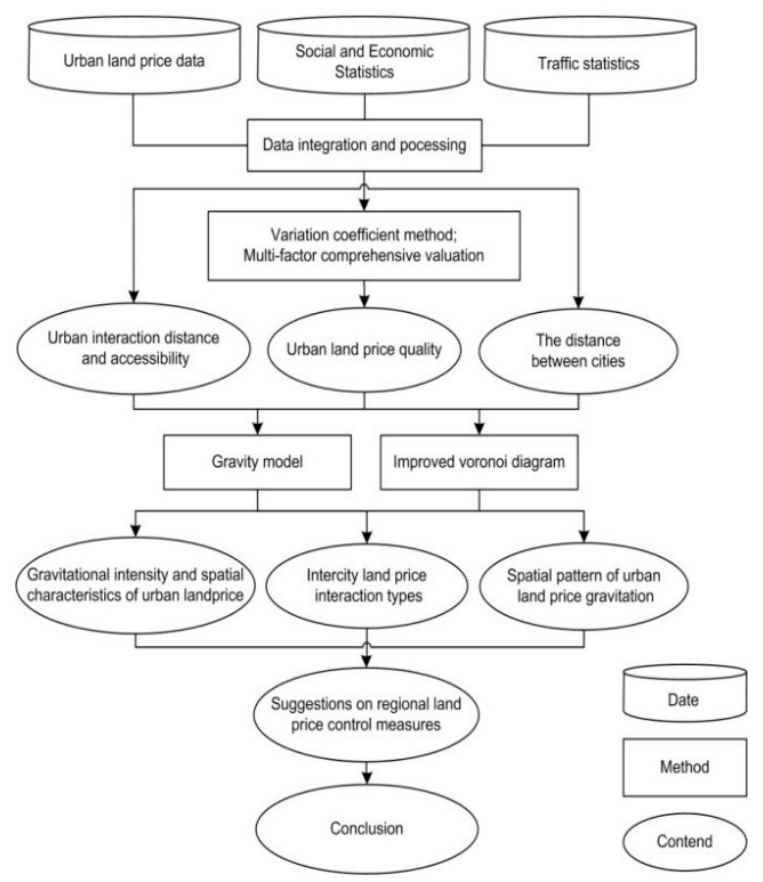

Figure 2. Flow chart of the study.

\subsection{Data and Pre-Processing}

\subsubsection{Social and Economic Data}

Urban land prices are affected by various factors including micro-land conditions, the land market mechanism, and government regulations and controls [84]. Under China's current non-competitive land market system, resource characteristics, and macro economy, real-estate speculation and interventions by government administrators often increase land prices to unreasonable levels. Thus, the land price in some cities does not match the real land value and the actual economic level of the city [85]. To eliminate the influence of unreasonable factors affecting land prices, we construct an index system for each factor influencing urban land prices and define the comprehensive effect of the index system as the corresponding "urban land-price quality" to reflect the objective level of the urban land price. 
The factors affecting urban land prices can be divided into general factors, regional factors, and individual factors based on their relationship with the land and the scope of influence. To objectively reflect the differences in land prices among various cities and eliminate unreasonable factors affecting land prices, we selected 14 indicators of urban location, degree of agglomeration, input-output levels, comprehensive service capacity, and land potential, and constructed a regional urban land-price quality index system based on the principles of regional differences, operability, and comparability [86] (see Table 1). The data for these indicators are derived from the China Urban Statistical Yearbook, the Beijing Statistical Yearbook, the Tianjin Statistical Yearbook, and the Hebei Economic Yearbook for 2017. The weights in the index system are based on the coefficient of variation method using Equations (2)-(5).

Table 1. Index system and weights for urban land-price quality.

\begin{tabular}{|c|c|c|c|c|c|}
\hline First-Grade Index & Weight & Second-Grade Index & Weight & Variable & Weight \\
\hline \multirow{2}{*}{ Urban location } & \multirow{2}{*}{0.1590} & \multirow{2}{*}{$\begin{array}{l}\text { External contact } \\
\text { Ability }\end{array}$} & \multirow{2}{*}{0.1590} & Freight volume & 0.0548 \\
\hline & & & & Passenger volume & 0.1041 \\
\hline \multirow{4}{*}{$\begin{array}{c}\text { Urban } \\
\text { agglomeration } \\
\text { degree }\end{array}$} & \multirow{4}{*}{0.2936} & Population & 0.0817 & $\begin{array}{c}\text { Nonagricultural } \\
\text { population }\end{array}$ & 0.0817 \\
\hline & & Built-up area & 0.0848 & Built-up area & 0.0848 \\
\hline & & $\begin{array}{l}\text { Non-agricultural } \\
\text { industries scale }\end{array}$ & 0.0843 & $\begin{array}{l}\text { Secondary and tertiary } \\
\text { industries income }\end{array}$ & 0.0843 \\
\hline & & Tertiary industry scale & 0.0428 & $\begin{array}{c}\text { The proportion of } \\
\text { tertiary industrial } \\
\text { output-value }\end{array}$ & 0.0428 \\
\hline \multirow{4}{*}{$\begin{array}{c}\text { Urban } \\
\text { input-output level }\end{array}$} & \multirow{4}{*}{0.3682} & \multirow[t]{2}{*}{ Investment level } & \multirow[t]{2}{*}{0.1702} & $\begin{array}{l}\text { Investment in fixed } \\
\text { assets of unit land }\end{array}$ & 0.0725 \\
\hline & & & & $\begin{array}{c}\text { Number of employees } \\
\text { in unit land use }\end{array}$ & 0.0977 \\
\hline & & \multirow[t]{2}{*}{ Output level } & \multirow[t]{2}{*}{0.1979} & $\begin{array}{c}\text { Retail sales of social } \\
\text { consumer goods per } \\
\text { unit land }\end{array}$ & 0.0927 \\
\hline & & & & $\begin{array}{c}\text { Financial revenue of } \\
\text { unit land }\end{array}$ & 0.1052 \\
\hline \multirow{3}{*}{$\begin{array}{c}\text { Urban } \\
\text { comprehensive } \\
\text { service capability }\end{array}$} & \multirow{3}{*}{0.1391} & Financial situation & 0.0436 & $\begin{array}{c}\text { Per capita bank } \\
\text { savings deposits }\end{array}$ & 0.0436 \\
\hline & & $\begin{array}{l}\text { Postal and } \\
\text { telecommunications } \\
\text { service ability }\end{array}$ & 0.0427 & $\begin{array}{l}\text { Per capita postal and } \\
\text { telecommunications } \\
\text { business volume }\end{array}$ & 0.0427 \\
\hline & & $\begin{array}{l}\text { Scientific and } \\
\text { technological level }\end{array}$ & 0.0529 & $\begin{array}{l}\text { The proportion of } \\
\text { expenditure on science } \\
\text { and education }\end{array}$ & 0.0529 \\
\hline $\begin{array}{c}\text { Urban land } \\
\text { potential }\end{array}$ & 0.0401 & Population density & 0.0401 & Population density & 0.0401 \\
\hline
\end{tabular}

\subsubsection{Traffic Data}

Related studies [87] show that distance may not necessarily play a major role in interactions between two regions, as the diversity of transport modes also affects interactions. Therefore, we considered the impact of transport modes and types of exchanges in measurements of the distance between cities. Based on the situation in the Beijing-Tianjin-Hebei region, rail and road are the main modes of transportation between cities, and the transportation of people and goods is the main type of regional exchange. Since air and maritime transportation are not often used in this area, we use rail and road transport modes and the transfer of people and goods to calculate the distance between cities. The data relating to inter-city transport distances were mainly obtained from the website of the inter-city railway operator, the China Traffic Atlas and the Hebei Highway Mileage Atlas published by the Transport Bureau of the Ministry of Railways of China. China's standard expressway speed of $120 \mathrm{~km} / \mathrm{h}$ is used as the average speed on the inter-city expressway and $350 \mathrm{~km} / \mathrm{h}$ is used as the 
average speed of rail transport. Data relating to passenger and freight volumes via both road and rail were obtained from the China Urban Statistical Yearbook and the Hebei Statistical Yearbook for 2017.

\subsection{Methods}

\subsubsection{Gravity Model of Urban Land Prices}

After the concept of "gravity" was introduced to the field of geography, the gravitational model became a classical means of quantifying spatial interactions between cities and measuring the influence of interactions among cities on land prices In the study region, urban land prices are the result of the combined effect of various social and economic factors. Due to the connection of social and economic factors among cities, there is bound to be some connection between urban land prices [88], and the level of land prices will be affected by interactions among cities. Therefore, we define the gravity model of urban land prices as follows:

$$
F_{i j}=\mathrm{r}_{i} M_{i} M_{j} / D_{i j}{ }^{2}
$$

where $F_{i j}$ is the gravitational value of land prices between cities $i$ and $j, M_{i}$ and $M_{j}$ are the quality of city $i$ and $j$, respectively, $D_{i j}$ is the distance between cities, and $r_{i}$ is the adjustment coefficient.

Various scholars have proposed different definitions of urban quality, and different index systems are used to represent urban quality in analyses of interactions in relation to the economy and population among cities [89]. In this study, urban quality is extended to urban land-price quality. Thus, urban land-price quality, distance between cities, and a regional adjustment coefficient are the three parameters of the urban land-price gravity model.

\section{(1). Urban land-price quality calculation}

Hedonic price theory states that land has different characteristics and, thus, its price is determined by all of these characteristics. Different combinations and numbers of features result in different land prices. This study decomposes various influential factors implied in the land price, constructs a high-correlation and reasonable combination of factors, and calculates the comprehensive value of factors using a comprehensive index evaluation method to characterize the land-price quality of the corresponding cities. To eliminate the influence of subjective factors, we use a variation coefficient to calculate the weights of urban land-price quality indicators. The variation coefficient method is a dynamic weight assignment method that determines weights based on the degree of variation of the evaluation index. The weight of each index changes with changes in the index [90,91]. The method is as follows.

(1) Calculate the mean value of the indicators:

$$
A_{j}=\frac{1}{n} \sum_{i=1}^{n} Y_{i j}(I=1,2,3, \ldots, n ; j=1,2,3, \ldots, m)
$$

(2) Calculate the standard deviation of the indicators:

$$
\sigma_{j}=\sqrt{\frac{1}{n-1} \sum_{i=1}^{n}\left(Y_{i j}-A_{j}\right)^{2}}
$$

(3) Determine the coefficient of variation:

$$
V_{j}=\frac{\sigma_{j}}{A_{j}}
$$


(4) Calculate the index weight:

$$
W_{j}=\frac{V_{j}}{\sum_{j=1}^{m} V_{j}}
$$

where $A_{j}$ is the average value of index $j, n$ is the number of cities in the study area, $m$ is the number of indexes in the evaluation system, $Y_{i j}$ is the standardized value of index $j$ of city $i, \sigma_{j}$ is the standard deviation, $V_{j}$ is the coefficient of variation, and $W_{j}$ is the weight of index $j$.

We used a comprehensive index to measure the quality of the urban land price:

$$
M_{i}=\sum_{j=1}^{m}\left(Y_{i j} \times W_{j}\right)
$$

where $M_{i}$ is the land-price quality of urban area $i, Y_{i j}$ is the standardized value of index $j$ of city $i, W_{j}$ is the weight of index $j$, and $m$ is the number of factors affecting the land price.

(2). Measuring the distance between cities

Following the distance measurement methods of previous studies [92], we take into account the influence of traffic conditions and modes of transport on the level of interconnection between cities, although we only calculate the distance between cities based on road and rail transportation modes and passenger and cargo flows. In relation to the distance between cities in terms of road and rail transport, the level of utilization of inter-city highways and railways is expressed by the passenger and freight volumes, respectively. The road and rail transport coefficients (weights) are determined based on the passenger and freight volume, respectively, of each city as a proportion of the total traffic volume. Thus, the distance between cities is defined as follows:

$$
\begin{gathered}
D_{i k}=D_{i k \text { Highway }} L_{\text {Highway }}+D_{i k \text { Railway }} L_{\text {Railway }}= \\
D_{i k \text { Highway }} \sqrt{\frac{H_{\text {Highway }}}{H_{\text {Highway }}+H_{\text {Railway }}} \times \frac{K_{\text {Highway }}}{K_{\text {Highway }}+K_{\text {Railway }}}}+D_{i k \text { Railway }} \sqrt{\frac{H_{\text {Railway }}}{H_{\text {Highway }}+H_{\text {Railway }}} \times \frac{K_{\text {Railway }}}{K_{\text {Highway }}+K_{\text {Railway }}}}
\end{gathered}
$$

where $D_{i k}$ is the comprehensive distance between city $i$ and city $k, D_{i k \text {-Highway }}$ and $D_{i k \text {-Railway }}$ are the road and rail distances between city $i$ and city $k$, respectively, $K$ is passenger volume, $H$ is freight volume, and $L_{\text {Highway }}$ and $L_{\text {Railway }}$ are the weights of road and rail transportation, respectively.

(3). Determining the adjustment coefficient

Based on previous studies using revisions of the gravity model [93], we use the accessibility between cities as the regional adjustment coefficient to revise the regional urban land-price gravity model. Accessibility relates to the possibility of passenger flows, cargo flows, capital flows, and information flows among cities. It is also an important measure of the degree of contact between cities. The accessibility coefficient between cities is calculated based on the distance between cities and the speed of travel on expressways and railways in China. The calculation process is as follows.

(1) The accessibility value of traffic mode $P$ in city $i$ :

$$
R_{i p}=D_{i p} / S_{i p}
$$

(2) The average value of $R_{i p}$ :

$$
\bar{R}_{p}=\frac{1}{\mathrm{n}} \sum_{i=1}^{n} R_{i p}
$$


(3) The accessibility coefficient of traffic mode $p$ in city $i$ :

$$
\mathrm{r}_{i p}=\bar{R}_{p} / R_{i p}
$$

(4) The accessibility coefficient of city $i$ :

$$
r_{i}=\sqrt{\mathrm{r}_{\mathrm{i} 1} \times r_{i 2} \ldots \ldots \mathrm{r}_{\mathrm{i} p}},
$$

where $D_{i p}$ is the traffic distance of traffic mode $P$ between city $i$ and other cities and $S_{i p}$ is the average speed of transportation mode $P$ from city $i$ to other cities.

\subsubsection{Voronoi Diagram Model Based on Fracture-Point Theory}

The Voronoi diagram model was first used to achieve spatial division of geographic features. A Voronoi diagram is irregular in space, and the Voronoi diagram model is a seamless, non-overlapping, distance segmentation method. It includes characteristics such as nearest neighbors, linearity, and local dynamics, and has become an important tool for spatial analysis in the field of geosciences. A Voronoi diagram is defined as follows:

$$
V_{i}=\left\{x \in K \mid d\left(x, P_{i}\right)<d\left(x, P_{j}\right), P i \neq P j\right\},
$$

where $\left\{P_{1}, P_{2}, \ldots, P_{n}\right\}$ is a discrete point in space where no two points coincide, no four points are in the same circle, and $d\left(P_{i}, P_{j}\right)$ is the Euclidean distance between any two points. In the polygonal subregion $V_{i}$ formed by the Voronoi diagram, the distance from any point $x$ to point $P$ is less than that from any other central point $\left(P_{i} \neq P_{j}\right)$ [94]. Following the conventional Voronoi diagram model, we set $\lambda_{i}(I=1,2, \ldots, n)$ as the weight of $p_{i}$, and $\lambda_{i}(I=1,2, \ldots, n)$ are the specified positive real numbers. The area of a Voronoi polygon is proportional to its weight. A conventional Voronoi graph is a special case in which all of the Voronoi points are weighted at the same time (see Figure $3 b$, where the number near each point represents the weight of that point). The formula is defined as follows:

$$
V_{n}\left(P_{i}, \lambda_{j}\right)=\bigcap_{j \neq i}\left\{P \mid d\left(P, P_{i}\right) / \lambda_{i}<d\left(P, P_{j}\right) / \lambda_{j}\right\}(I=1,2, \ldots, n) .
$$

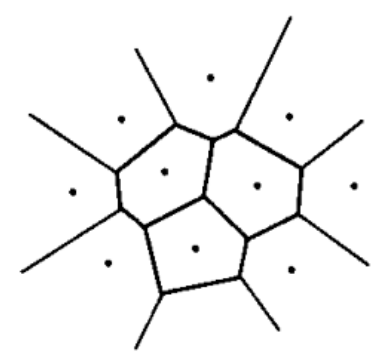

(a)

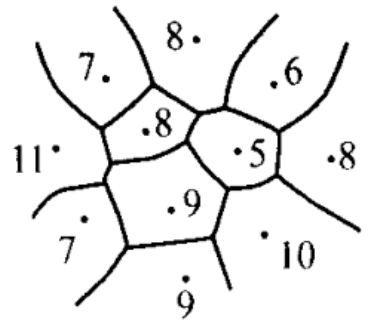

(b)

Figure 3. (a) Conventional Voronoi diagram, and (b) weighted Voronoi diagram.

Fracture-point theory is mostly used to explain the comparative strengths of regional-urban interactions. The basic idea is that the gravitational attraction between cities is positively correlated with the size of the largest city and negatively correlated with the square of distance. The location of the breaking point in the range of influence between cities can be expressed as follows:

$$
R_{a}=R_{a b} /\left(1+\sqrt{P_{b} / P_{a}}\right), R_{b}=R_{a b} /\left(1+\sqrt{P_{a} / P_{b}}\right),
$$

where $R_{a}$ and $R_{b}$ are the distance from cities $a$ and $b$, respectively, to the breaking point, $R_{a b}$ is the distance between the cities, and $P_{a}$ and $P_{b}$ are the quality of cities $a$ and $b$, respectively. 
In the process of Voronoi space partitioning, the ratio of the spacing between the point in the weighted Voronoi graph grid and the spacing between the point and the adjacent grid generators is less than the ratio of the weights of the two generators. This study combines fracture-point theory with the conventional Voronoi chart model, defines urban quality as the quality of the urban land price, and divides the influence scope using a weighted Voronoi map of urban land-price quality. Based on the weighted Voronoi diagram model, the ratio of the distance from the breaking point between two adjacent cities to the two cities is the ratio of the square root of the land-price quality of the two cities. The breaking point naturally expands to form a breaking arc, thus forming the gravitational boundary of the land price between the two cities. This method overcomes the problem of arbitrariness in the formation of urban boundaries using conventional Voronoi diagrams [95].

\section{Results}

\subsection{Urban Land-Price Quality}

We calculated a comprehensive index of the land-price quality of each city. The land-price qualities of Beijing and Tianjin are 89.22 and 54.38, respectively, which are much higher than those of other cities, reflecting their central positions in the region (see Figure 4). Shijiazhuang, Langfang, Qinhuangdao, and Tangshan have relatively high land-price qualities, ranging from 16.49-19.43. The land-price qualities of Baoding, Cangzhou, and Handan are in the medium range, while the values for the other cities are relatively low, ranging from 3.89-11.19. These results indicate that the land-price levels in Beijing and Tianjin are significantly higher than those of other cities, and that urban land prices in Hebei Province are significantly lower. Beijing and Tianjin have tremendous advantages over the other cities in terms of economic development, such as convenient transportation and communication systems, well-developed infrastructure, and strong capital markets. The rapid development of the real-estate economy in recent years has stimulated other economies to move towards Beijing and Tianjin. Therefore, the polarization between Beijing, Tianjin, and Hebei has arisen as a result of the allocation of land resources and the level of development of the land market.

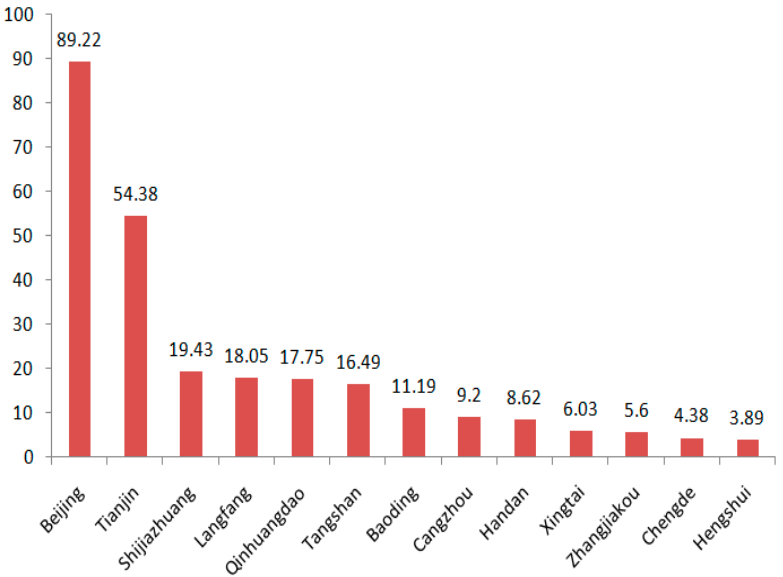

(a) Histogram

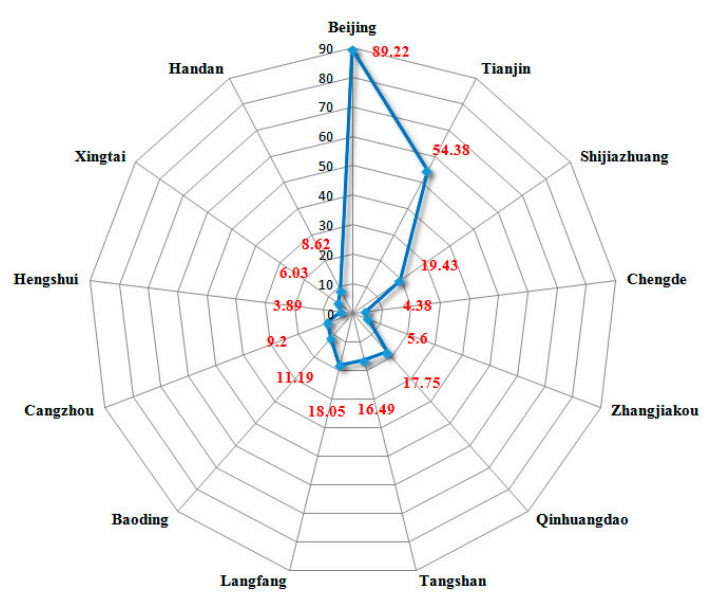

(b) Spider chart

Figure 4. Quality of urban land prices in the Beijing-Tianjin-Hebei region.

Pearson correlation analysis was used to test whether the quality of urban land prices can objectively reflect the level of urban land prices. The results revealed that the correlation coefficient between urban land-price quality and comprehensive land-price level is $0.906(p<0.01)$, indicating that they are positively correlated (see Table 2 and Figure 5). Thus, the quality of urban land prices can comprehensively and objectively reflect the characteristics of urban land prices in the region. 
Table 2. Correlation between urban land prices and urban land-price quality.

\begin{tabular}{cccc}
\hline & & Land Price Quality & Land Price Level \\
\hline \multirow{2}{*}{ Land price quality } & Pearson Correlation & 1 & $0.906^{* *}$ \\
& Sig. (2-tailed) & & 0.000 \\
& $\mathrm{~N}$ & 13 & 13 \\
\hline \multirow{2}{*}{ Land price level } & Pearson Correlation & $0.906^{* *}$ & 1 \\
& Sig. (2-tailed) & 0.000 & 13 \\
\hline
\end{tabular}

** Significant at the 0.01 level (two-tailed).

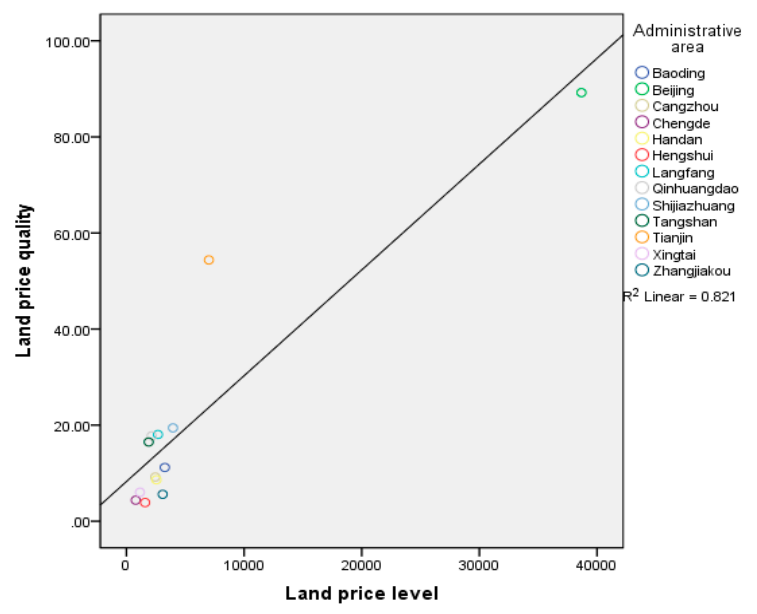

Figure 5. Scatter plot of the correlation between urban land prices and urban land-price quality.

\subsection{Urban Interaction Distance and Accessibility Coefficients}

Table 3 shows the interaction distance and accessibility indices between cities. Beijing to Langfang and Tianjin to Langfang have higher accessibility coefficients of 3.18 and 3.14, respectively, because of their closer proximity and convenient connections, which fully reflects the locational advantage of Langfang and its central position in the traffic network. Assuming that the Beijing-Tianjin-Hebei region is a closed region, the greater the accessibility coefficient between a city and other cities in the region, the greater the accessibility of the city. Based on the number of cities whose accessibility coefficient is greater than 1, the accessibility level of each city is further classified (see Figure 6). In addition to Langfang, cities with high accessibility include Shijiazhuang, Baoding, and Hengshui. There are six neighbor cities whose accessibility coefficients in relation to these three cities are greater than or equal to 1. Cities with medium accessibility are Beijing, Tianjin, Tangshan, Zhangzhou, and Xingtai. There are four or five neighbor cities whose accessibility coefficients in relation to these five cities are greater than or equal to 1 . Cities with poor accessibility are Qinhuangdao, Handan, Zhangjiakou, and Chengde. There are only two or three neighbor cities whose accessibility coefficients in relation to these four cities are greater than or equal to 1 (see Table 3). Accessibility among cities in the Beijing-Tianjin-Hebei region is mostly affected by existing transportation conditions. The accessibility levels of Beijing, Tianjin, Central Hebei, and coastal cities are higher than those of cities in Southern and Northern Hebei. Accessibility levels between cities in Central and Southern Hebei are relatively high, while those between the peripheral cities are generally low. Langfang, Baoding, and Shijiazhuang are the key links between the northern and southern areas of the Beijing-Tianjin-Hebei region. 
Table 3. Urban interaction distances $(\mathrm{km})$ and accessibility coefficients in the Beijing-Tianjin-Hebei region.

\begin{tabular}{|c|c|c|c|c|c|c|c|c|c|c|c|c|c|}
\hline City & Beijing & Tianjin & Shijiazhuang & Chengdu & Zhangjiakou & Qinhuangdao & Tangshan & Langfang & Baoding & Cangzhou & Hengshui & Xingtai & Handan \\
\hline Beijing & - & $136 / 1.48$ & $284 / 0.72$ & $238 / 0.82$ & $218 / 1.05$ & $288 / 0.7$ & $184 / 1.06$ & $63 / 3.18$ & $147 / 1.35$ & 2310.82 & $270 / 0.69$ & $399 / 0.66$ & $473 / 0.62$ \\
\hline Tianjin & $136 / 1.48$ & & $354 / 0.6$ & $315 / 0.65$ & $343 / 0.67$ & $259 / 0.83$ & $124 / 1.78$ & $78 / 3.14$ & 197/1 & $121 / 1.78$ & $252 / 0.7$ & $407 / 0.58$ & $435 / 0.55$ \\
\hline Shijiazhuang & $284 / 0.72$ & $354 / 0.6$ & & $523 / 0.71$ & $476 / 0.8$ & $587 / 0.65$ & $455 / 0.79$ & $284 / 1.24$ & $137 / 2.82$ & $232 / 1.48$ & $145 / 2.71$ & $124 / 2.75$ & 1721.86 \\
\hline Chengde & $238 / 0.82$ & $315 / 0.65$ & $523 / 0.71$ & 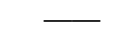 & $398 / 0.92$ & $376 / 1.03$ & $256 / 0.84$ & 299/1.21 & $385 / 0.68$ & $409 / 0.82$ & $501 / 0.6$ & $630 / 0.54$ & $686 / 0.5$ \\
\hline Zhangjiakou & $218 / 1.05$ & $343 / 0.67$ & $476 / 0.8$ & $398 / 0.92$ & - & $506 / 0.73$ & $405 / 0.69$ & $285 / 1.43$ & $374 / 0.75$ & $512 / 0.8$ & $460 / 0.72$ & $534 / 0.65$ & $608 / 0.58$ \\
\hline Qinhuangdao & $288 / 0.7$ & $259 / 0.83$ & $587 / 0.65$ & $376 / 1.03$ & $506 / 0.73$ & - & $141 / 1.79$ & $327 / 1.13$ & $436 / 0.83$ & $367 / 0.98$ & $513 / 0.7$ & $676 / 0.62$ & $713 / 0.52$ \\
\hline Tangshan & $184 / 1.06$ & $124 / 1.78$ & $455 / 0.79$ & $256 / 0.84$ & $405 / 0.69$ & $141 / 1.79$ & - & $193 / 1.38$ & $296 / 0.88$ & $225 / 1.11$ & $361 / 0.73$ & $512 / 0.65$ & $561 / 0.6$ \\
\hline Langfang & $63 / 3.18$ & $78 / 3.14$ & $284 / 1.24$ & $299 / 1.21$ & $285 / 1.43$ & $327 / 1.13$ & $193 / 1.38$ & - & $144 / 1.59$ & $170 / 1.66$ & 249/1.11 & $391 / 0.99$ & $453 / 0.88$ \\
\hline Baoding & $147 / 1.35$ & 197/1 & $137 / 2.82$ & $385 / 0.68$ & $374 / 0.75$ & $436 / 0.83$ & $296 / 0.88$ & $144 / 1.59$ & - & $166 / 0.95$ & $156 / 1.14$ & 249/1.05 & $297 / 0.92$ \\
\hline Cangzhou & $231 / 0.82$ & $121 / 1.78$ & $232 / 1.48$ & $409 / 0.82$ & $512 / 0.8$ & $367 / 0.98$ & $225 / 1.11$ & $170 / 1.66$ & $166 / 0.95$ & - & $147 / 1.21$ & $310 / 0.86$ & $351 / 0.81$ \\
\hline Hengshui & $270 / 0.69$ & $252 / 0.7$ & $145 / 2.71$ & $501 / 0.6$ & $460 / 0.72$ & $513 / 0.7$ & $361 / 0.73$ & 249/1.11 & $156 / 1.14$ & $147 / 1.21$ & - & $178 / 1.24$ & $261 / 1.22$ \\
\hline Xingtai & $399 / 0.66$ & $407 / 0.58$ & $124 / 2.75$ & $630 / 0.54$ & $534 / 0.65$ & $676 / 0.62$ & $512 / 0.65$ & $391 / 0.99$ & $249 / 1.05$ & $310 / 0.86$ & $178 / 1.24$ & - & $62 / 2.1$ \\
\hline Handan & $473 / 0.62$ & $435 / 0.55$ & 1721.86 & $686 / 0.5$ & $608 / 0.58$ & $713 / 0.52$ & $561 / 0.6$ & $453 / 0.88$ & $297 / 0.92$ & $351 / 0.81$ & $261 / 1.22$ & $62 / 2.1$ & - \\
\hline
\end{tabular}




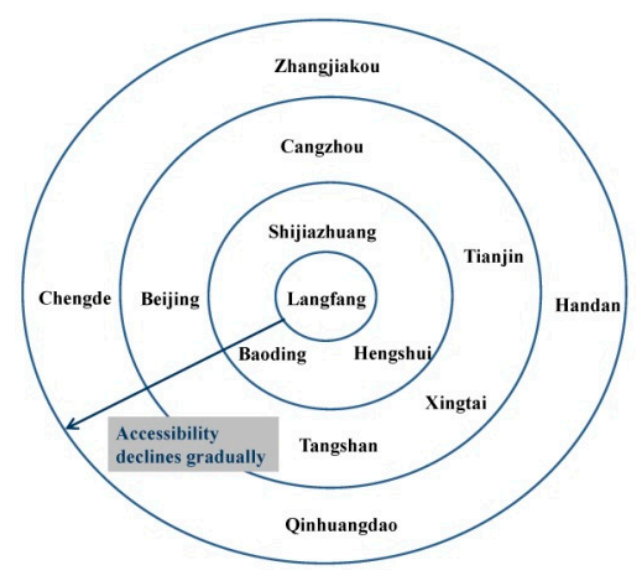

Figure 6. Inter-city accessibility level.

\subsection{Urban Land-Price Gravity}

Using the abovementioned urban land-price quality and interaction distance data, the land-price gravity model is used to calculate the land-price gravity between cities (see Table 4). Figure 7 shows the gravitational intensity map of urban land prices in the Beijing-Tianjin-Hebei region. Each city has its most gravitational city, which is known as the "most connected city." Each city is connected with its most connected city by an arrowed line. The arrowed line points to the city, while the origin of the arrowed line is its most connected city. The distribution of the strongest gravitational connection is obtained by analyzing the direction, quantity, and structure of the arrowed lines, thereby reflecting the gravitational characteristics of the land price between cities (see Figure 8).

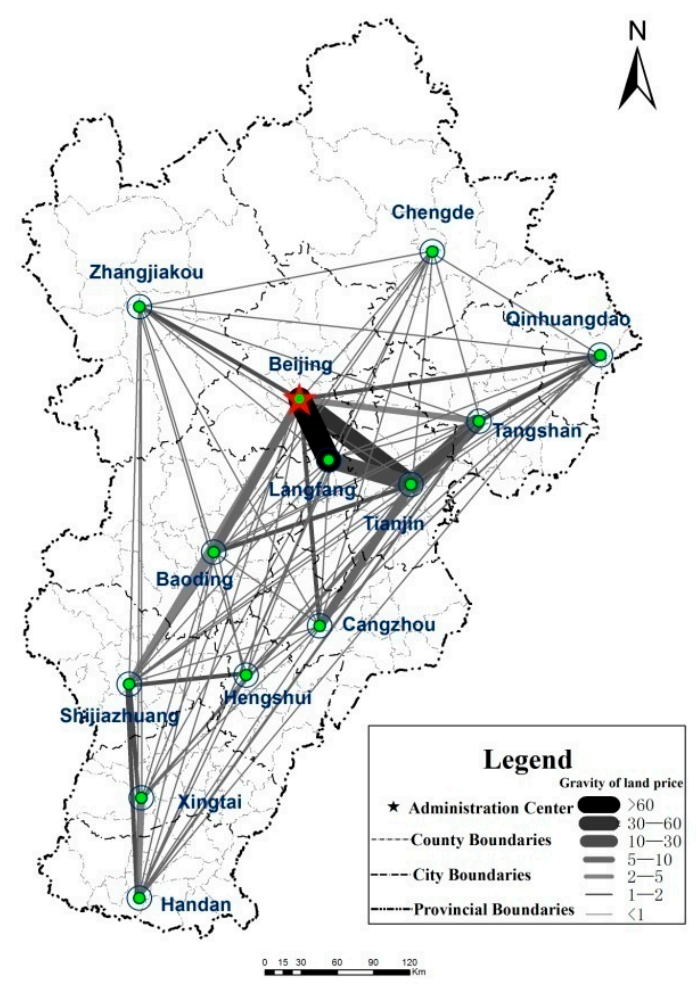

Figure 7. Gravity intensity of urban land prices in the Beijing-Tianjin-Hebei region. 
Table 4. Gravity matrix of urban land prices in the Beijing-Tianjin-Hebei region.

\begin{tabular}{|c|c|c|c|c|c|c|c|c|c|c|c|c|c|}
\hline City & Beijing & Tianjin & Shijiazhuang & Chengdu & Zhangjiakou & Qinhuangdao & Tangshan & Langfang & Baoding & Cangzhou & Hengshui & Xingtai & Handan \\
\hline Beijing & - & 38.82 & 2.44 & 0.61 & 1.32 & 1.04 & 4.99 & 63.35 & 5.95 & 1.26 & 0.33 & 0.22 & 0.31 \\
\hline Tianjin & 38.82 & - & 0.47 & 0.17 & 0.23 & 0.89 & 11.24 & 24.87 & 1.50 & 6.09 & 0.23 & 0.11 & 0.20 \\
\hline Shijiazhuang & 2.44 & 0.47 & - & 0.02 & 0.05 & 0.02 & 0.12 & 0.25 & 2.89 & 0.46 & 1.43 & 1.95 & 1.82 \\
\hline Chengde & 0.61 & 0.17 & 0.02 & - & 0.02 & 0.02 & 0.11 & 0.06 & 0.02 & 0.02 & 0.00 & 0.00 & 0.01 \\
\hline Zhangjiakou & 1.32 & 0.23 & 0.05 & 0.02 & - & 0.02 & 0.06 & 0.12 & 0.04 & 0.02 & 0.01 & 0.01 & 0.01 \\
\hline Qinhuangdao & 1.04 & 0.89 & 0.02 & 0.02 & 0.02 & - & 1.16 & 0.07 & 0.03 & 0.05 & 0.01 & 0.01 & 0.01 \\
\hline Tangshan & 4.99 & 11.24 & 0.12 & 0.11 & 0.06 & 1.16 & - & 0.59 & 0.19 & 0.36 & 0.04 & 0.03 & 0.04 \\
\hline Langfang & 63.35 & 24.87 & 0.25 & 0.06 & 0.12 & 0.07 & 0.59 & - & 0.73 & 0.47 & 0.06 & 0.04 & 0.05 \\
\hline Baoding & 5.95 & 1.50 & 2.89 & 0.02 & 0.04 & 0.03 & 0.19 & 0.73 & - & 0.41 & 0.19 & 0.11 & 0.14 \\
\hline Cangzhou & 1.26 & 6.09 & 0.46 & 0.02 & 0.02 & 0.05 & 0.36 & 0.47 & 0.41 & - & 0.20 & 0.06 & 0.10 \\
\hline Hengshui & 0.33 & 0.23 & 1.43 & 0.00 & 0.01 & 0.01 & 0.04 & 0.06 & 0.19 & 0.20 & - & 0.09 & 0.13 \\
\hline Xingtai & 0.22 & 0.11 & 1.95 & 0.00 & 0.01 & 0.01 & 0.03 & 0.04 & 0.11 & 0.06 & 0.09 & - & 4.16 \\
\hline Handan & 0.31 & 0.20 & 1.82 & 0.01 & 0.01 & 0.01 & 0.04 & 0.05 & 0.14 & 0.10 & 0.13 & 4.16 & - \\
\hline
\end{tabular}




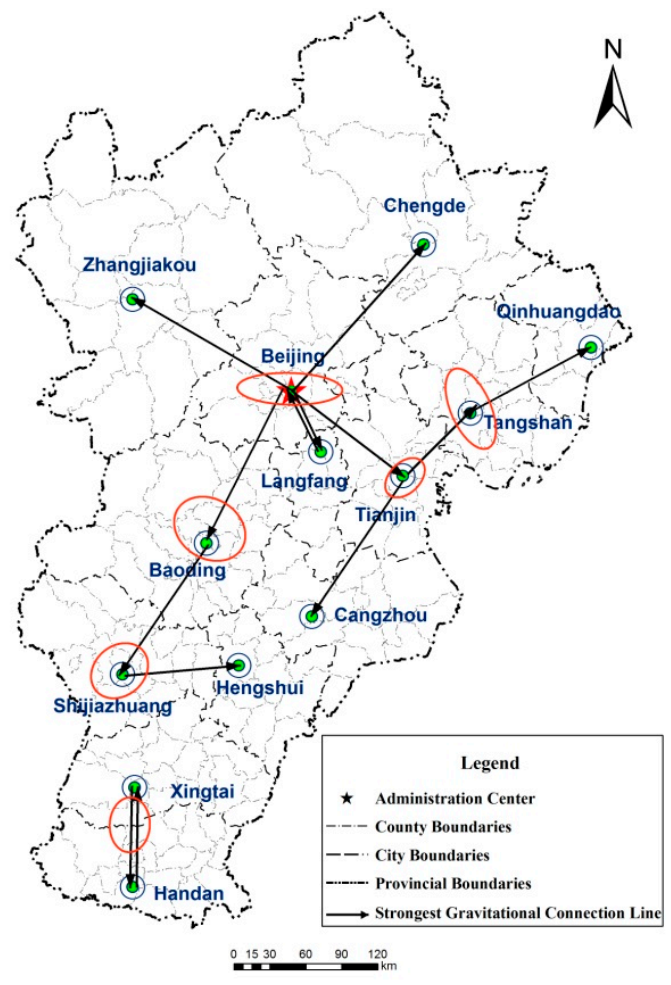

Figure 8. Distribution of the strongest gravitational connection lines.

\subsection{Gravitational Pattern of Urban Land Prices}

The range of influence of urban land prices is composed of multiple closed polygons using the weighted Voronoi diagram model. These polygons are formed by taking the square root of the urban land-price quality as the expansion speed and the urban center as the growth core around which expansion occurs (see Figure 9). Each city has a range of land prices, and the boundaries of the range exhibit a particular radian (see Figure 9). The boundaries always bend toward cities with stronger land-price centrality, that is, toward more attractive cities. The influence of the city increases in tandem with the radian around the city. For example, the boundaries of Zhangjiakou, Chengde, Langfang, and Baoding land prices are obviously inclined toward Beijing, which indicates that these cities have established a close relationship with and are greatly influenced by Beijing. Similarly, the land prices of Qinhuangdao, Cangzhou, and Hengshui are greatly influenced by Tangshan, Tianjin, and Shijiazhuang, respectively. The boundaries of land-price influence in Xingtai are convex toward Shijiazhuang and Handan, and the southern arc is larger, which indicates that Handan has a greater influence on Xingtai than Shijiazhuang. If the curvature tends to zero, this indicates that the gravitational attraction of urban land prices at both ends of the demarcation line is basically balanced, for example, Beijing and Tianjin, Tianjin and Tangshan, Cangzhou and Hengshui, and Baoding and Shijiazhuang exhibit land-price gravity balance.

Based on the demarcation line denoting gravitational equilibrium of land prices among cities, we divided the cities into clusters. The core city in each cluster is the city with the most influential land prices (see Figure 10). The Beijing-centered city cluster is mainly distributed in the northwest of the Beijing-Tianjin-Hebei region and occupies nearly half of the region. The land price in this cluster affects 71 towns under the jurisdiction of Beijing, Tianjin, Chengde, Zhangjiakou, Langfang, and Baoding. The Tianjin-centered city cluster and the Shijiazhuang-centered city cluster are distributed in the eastern and southern areas of the city cluster around Beijing, and have a secondary influence covering 30 towns under Tianjin, Langfang, Hengshui, and Cangzhou, and 35 towns under Shijiazhuang, Baoding, and Xingtai, respectively. The Handan-centered city cluster and the Tangshan-centered city cluster have the smallest impact areas in the northeast and south of the Beijing-Tianjin-Hebei region. They have 
relatively weak links with other regions, covering 30 towns under Xingtai and Handan, and 17 towns under Tangshan and Qinhuangdao, respectively (see Table 5).

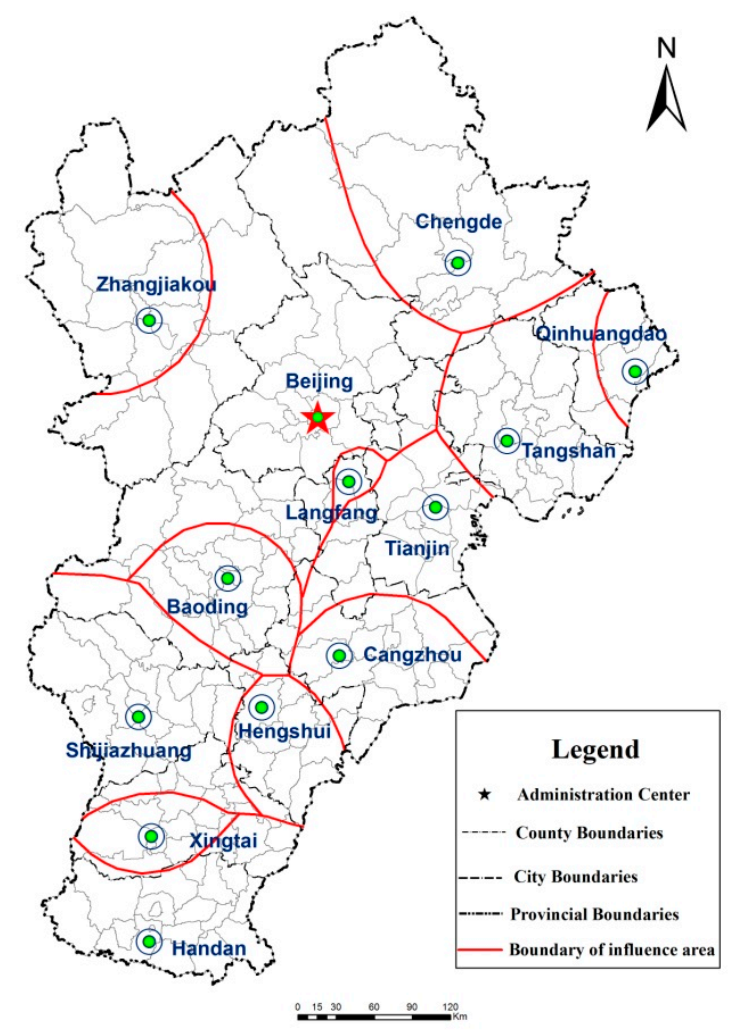

Figure 9. Gravitational range of urban land prices.

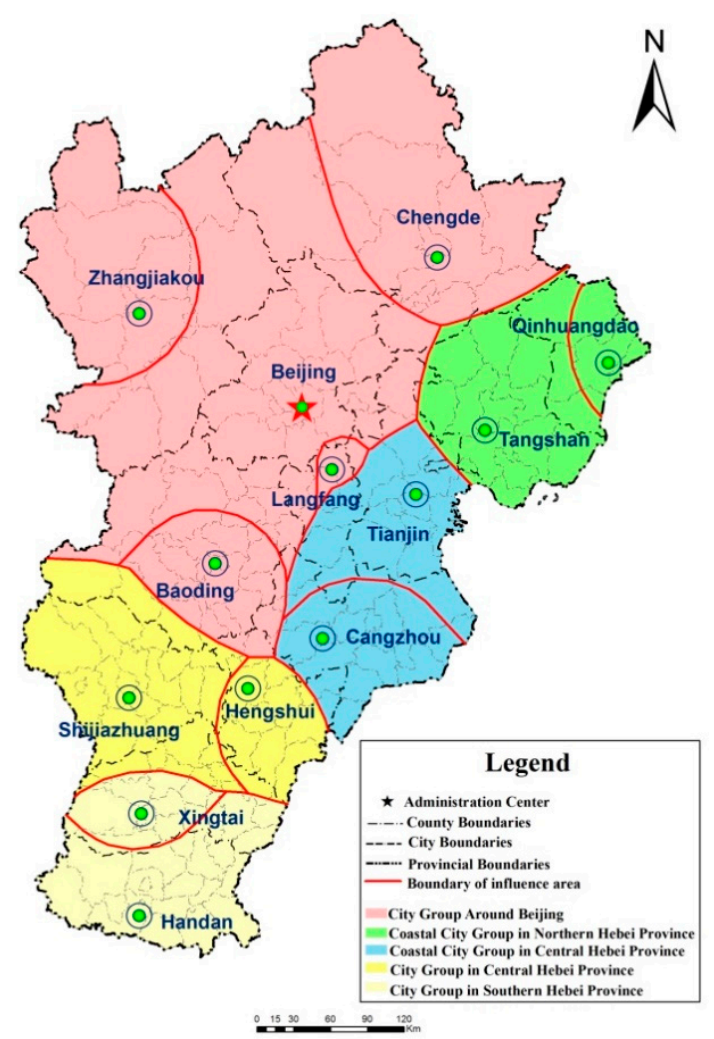

Figure 10. Classification of gravitational groups of urban land prices. 
Table 5. Scope of influence of urban land-price groups in Beijing, Tianjin, and Hebei.

\begin{tabular}{|c|c|c|}
\hline Name of Group & Central City & Scope of Influence (County) \\
\hline \multirow{8}{*}{ City cluster around Beijing } & \multirow{8}{*}{ Beijing } & Beijing district and all the counties under its jurisdiction \\
\hline & & Chengde district and all the counties under its jurisdiction \\
\hline & & Zhangjiakou district and all the counties under its jurisdiction \\
\hline & & Counties under Tianjin's jurisdiction: Jing \\
\hline & & Counties under Cangzhou's jurisdiction: Suning \\
\hline & & Counties under Hengshui's jurisdiction: Anping, Raoyang \\
\hline & & $\begin{array}{l}\text { Langfang district and counties under its jurisdiction: Sanhe, Guan, Yongqing, Xianghe, Hui Autonomous } \\
\text { County of Dachang }\end{array}$ \\
\hline & & $\begin{array}{l}\text { Baoding district and counties under its jurisdiction: Anguo, Boye, Li, Wangdu, Qingyuan, Anxin, Shunping, } \\
\text { Gaoyang, Tang, Mancheng, Xushui, Rongcheng, Xiong, Dingxing, Gaobeidian, Yi, Zhuozhou, Laiyuan, Laishui }\end{array}$ \\
\hline \multirow{2}{*}{ Northern coastal city cluster } & \multirow{2}{*}{ Tangshan } & Tangshan district and all the counties under its jurisdiction \\
\hline & & Qinhuangdao district and all the counties under its jurisdiction \\
\hline \multirow{4}{*}{ Central coastal city cluster } & \multirow{4}{*}{ Tianjin } & Counties under Hengshui's jurisdiction: Fucheng \\
\hline & & Counties under Langfang's jurisdiction: Bahou, Dacheng, Wenan \\
\hline & & $\begin{array}{l}\text { Counties under Tianjin's jurisdiction: Wuqing District, Dagang District, Baodi District, Jinnan District, Jinghai } \\
\text { County, Xiqing District, Tianjin Urban District, Tanggu District, Dongli District, Beichen District, Hangu District } \\
\text { and Ninghe County }\end{array}$ \\
\hline & & $\begin{array}{l}\text { Cangzhou district and counties under Cangzhou's jurisdiction: Dongguang, Wuqiao, Yanshan, Nanpi, Botou, } \\
\text { Huanghua, Xian, Haixing, Cangxian, Hejian, Qingxian, Renqiu, Mengcun Hui Autonomous County }\end{array}$ \\
\hline \multirow{4}{*}{ Central city cluster } & \multirow{4}{*}{ Shijiazhuang } & Shijiazhuang and all the counties under its jurisdiction \\
\hline & & Counties under Xingtai's jurisdiction: Nangon, Lincheng, Xinhe, Baixiang, Ningjin \\
\hline & & $\begin{array}{l}\text { Counties under Hengshui's jurisdiction: Wuyi, Shenzhou, Wuqiang, Taocheng, Jingxian, Gucheng, Zaoqiang, } \\
\text { Jizhou }\end{array}$ \\
\hline & & Counties under Baoding's jurisdiction: Dingzhou, Quyang, Fuping \\
\hline \multirow[b]{2}{*}{ Southern city cluster } & \multirow[b]{2}{*}{ Handan } & Handan and all the counties under its jurisdiction \\
\hline & & $\begin{array}{l}\text { Counties under Xingtai's jurisdiction: Shahe, Linxi, Xingtai, Nanhe, Pingxiang, Qinghe, Ren, Xingtai, } \\
\text { Guangzong, Weixian, Neiqiu, Julu }\end{array}$ \\
\hline
\end{tabular}




\section{Discussion}

\subsection{Gravitational Characteristics of Land Prices}

\subsubsection{Characteristic of Gravitational Intensity}

The gravitational intensity of land prices between cities is quite different in the Beijing-Tianjin-Hebei region. The gravitational value is only greater than 50 in Beijing and Langfang, which have the highest gravitational intensity of 63.35. Three groups of gravitational values are in the range of 10-50, including Beijing and Tianjin (38.82), Tianjin and Langfang (24.87), and Tianjin and Tangshan (11.24). Fourteen groups of gravitational values are in the range of 1-10, including Tianjin and Cangzhou, Beijing and Baoding, Beijing and Tangshan, Handan and Xingtai, Shijiazhuang and Baoding, Beijing and Shijiazhuang, Xingtai and Shijiazhuang, Shijiazhuang and Handan, Tianjin and Baoding, Shijiazhuang and Hengshui, Beijing and Zhangjiakou, Beijing and Cangzhou, Tangshan and Qinhuangdao, and Beijing and Qinhuangdao, with a gravitational value in the range of 1.04-6.09. There are 60 groups with gravitational values of less than 1 . Shijiazhuang, the capital of Hebei Province, has gravitational values of 2.44 and 2.89 with Beijing and Baoding, respectively, but gravitational values of only 1.43-1.95 with Xingtai, Handan, and Hengshui. In Hebei Province, the highest inter-city gravity value is only 2.89 , and urban pairs with gravitational values greater than 1 account for only $7.8 \%$ of the total. The gravitational attraction of Beijing, Tianjin, and Langfang is much higher than that of other cities, while the gravitational attraction of cities in Hebei Province is relatively weak, and few cities have a strong interaction in terms of land prices.

\subsubsection{Spatial Characteristic of Gravitation}

Table 4 and Figure 7 show the clear differences in urban land-price gravity in the Beijing-Tianjin-Hebei region. There are five cities with a gravitational intensity of greater than 1 in the vicinity of Beijing and Tianjin. Most of these cities are distributed around Beijing and Tianjin, have better accessibility to Beijing and Tianjin, and are greatly affected by the radiation of land-price levels in Beijing and Tianjin. The gravitational attraction of land prices among Beijing, Tianjin, Langfang, and Tangshan is higher, with gravitational values ranging from 11.24-63.35, than those of the northern and southern regions. Spatially, these four cities have become the centers of land-price connection nodes and constitute the spatial focus of the gravitational development of land prices in the Beijing-Tianjin-Hebei urban agglomeration. In addition to Beijing and Tianjin, only six pairs of cities have a gravitational intensity of greater than 1 in Hebei Province, mainly distributed in the central and southern regions. Their gravitational values range from 1.43-4.16, forming land-price interaction areas mainly in Shijiazhuang, Baoding, Xingtai, and Handan cities, and the gravitational intensity of their land prices is on the low side. The gravitational attraction of land prices among cities such as Chengde, Zhangjiakou, Qinhuangdao, Cangzhou, and Hengshui is less than 1, and the gravitational intensity of these cities is weakest. A weak gravitational zone exists in the eastern and northern regions. The gravity of land prices in the Beijing-Tianjin-Hebei urban agglomeration shows the spatial differentiation characteristics of "More cities with weak gravity and fewer cities with strong gravity, with the cities around Beijing and Tianjin closely connected, while the peripheral cities are loosely connected."

\subsection{Gravitational Types of Urban Land Prices}

The arrowed lines link the most connected cities and express the interaction of land prices between cities in the region. The types of interactions in terms of urban land prices can be determined by the number and direction of the arrows. Using the phenomenon of heat transfer as a model, we identified three types of land-price interactions: radiation, conduction, and convection. 


\subsubsection{Radiation Land Price}

The radiation land-price type occurs when the land price of one city has the greatest attraction effect on the land prices of other cities around it. It is the common aggregation target of the elements of the land market of the surrounding cities. The influence of the land-price radiation city on the cities it attracts is seen to play the lead role in the land-price level. Beijing has the five strongest gravitational connection lines, the largest number of radiating cities (see Figure 8), and the highest gravitational value of land prices in relation to other cities in the spatial interaction unit and, thus, acts as the regional agglomeration center. Beijing is the "midstream pillar" of land-price levels and land market development in the urban agglomeration and plays the lead role in attracting surrounding cities. Similarly, Tianjin has three of the strongest gravitational links, each of these forming secondary radiation centers. Beijing's land-price radiation cities are all distributed around Beijing, including Tianjin, Langfang, Baoding, Zhangjiakou, and Chengde. Tianjin's land-price radiation cities include Tangshan and Zhangzhou.

The gravitational intensity of land prices and the interaction distance between Tianjin and Beijing are 38.82 and $136 \mathrm{~km}$, respectively. Tianjin's development is positioning the city as the economic center of Northern China, and in recent years, Tianjin has become an important alternative city for Beijing's environmental technology, medical, and business industries. The transportation advantage is most significant in Langfang, which is $63 \mathrm{~km}$ and $78 \mathrm{~km}$ from Beijing and Tianjin, respectively, and has a gravitational intensity in relation to Beijing and Tianjin of 63.35 and 24.87, respectively. Langfang has become a major focal area for emerging strategic industries and modern service industries that have migrated from Beijing. Baoding is located in the middle of the Beijing-Tianjin-Hebei region, $147 \mathrm{~km}$ from Beijing, and its gravitational pull from Beijing is 5.95. Baoding has undertaken some functional relief tasks for administrative institutions, institutions of higher learning, research institutes, and medical care institutions in Beijing. Zhangjiakou and Chengde are $218 \mathrm{~km}$ and $238 \mathrm{~km}$, respectively, from Beijing, and their gravitational pull from Beijing is 1.32 and 0.61 , respectively. These two cities have weak economic levels, but their ecological environment is excellent. They are characteristic functional cities serving Beijing, and play an important role in protecting the ecological environment in the northwest of the Beijing-Tianjin-Hebei region. Affected by Beijing's economic radiation, Zhangjiakou and Chengde mainly develop green industries, such as new energy, tourism services, and leisure, and are characteristic of cities that serve Beijing. Tangshan and Cangzhou are mainly affected by Tianjin's radiation, their land price gravitation with Tianjin being 11.24 and 6.09, respectively. Tangshan and Cangzhou offer convenient maritime transportation and, thus, are focusing on the development of marine economic, biomedicine, and logistics industries, and are important hubs for overseas trade by organizations in both Beijing and Tianjin.

Since 2014, Langfang, Baoding, Zhangiiakou, Chengde, Tangshan, and Cangzhou have undertaken about 3290 industrial projects that have been transferred from Beijing and Tianjin, accounting for $21.2 \%$ of all industrial projects transferred. Due to the increasing demand for industrial land in Beijing and Tianjin, the land prices in cities around Beijing and Tianjin, such as Langfang, Baoding, Tangshan, and Cangzhou increased significantly in 2014-2017, with growth rates of 31.4\%, 21.7\%, $25.3 \%$, and 34.2\%, respectively, similar to that of Beijing (38.0\%). The 2022 Winter Olympics will be held in Zhangjiakou, and Beijing's support for Zhangjiakou in terms of economic development, land-use policy, and infrastructure construction is constantly increasing. This has led to a significant increase in land prices in Zhangjiakou, which recorded a growth rate of 196.7\% in 2014-2017. It can be seen that Langfang, Baoding, Zhangjiakou, Chengde, Tangshan, and Cangzhou have become the main radiation areas of Beijing and Tianjin in the process of the coordinated development of the Beijing-Tianjin-Hebei region.

\subsubsection{Conduction Land Price}

The conduction land-price type occurs when two cities have the greatest gravitational relationship between themselves. The land price of conductive cities in the Beijing-Tianjin-Hebei region is relatively 
high. Conductive cities are usually the sub-centers of the region in terms of economic development. Shijiazhuang, Baoding, and Tangshan have inherited the gravitational connection of land prices from Beijing, Tianjin, Qinhuangdao, and Hengshui and, thus, have become conductive cities. As the "third pole" of the Beijing-Tianjin-Hebei urban agglomeration, Shijiazhuang enables the cooperation of society, the economy, and the transportation system in the coordinated development of the Beijing-Tianjin-Hebei urban agglomeration. Shijiazhuang plays an important role in connecting the eastern and western areas and the southern and northern areas of the region. It is the most attractive city for Hengshui, and is attracted by Baoding. Thus, it has become the transmission node between these two cities. Tangshan is attracted by Beijing and Tianjin, and actively linked with Qinhuangdao, thereby becoming the transmission node between Tianjin and Qinhuangdao. As an important part of Beijing's industrial transfer, Baoding is actively connected with Beijing's high-end resources, and has obvious interactions with Shijiazhuang in the southern area of the region. Thus, it has become the transmission node between Beijing and Shijiazhuang.

Baoding is the most attractive city for Shijiazhuang, and is also the transportation hub connecting Shijiazhuang with Beijing. The interaction distance between Baoding and Shijiazhuang is $137 \mathrm{~km}$, and the gravitational value is 2.89. Superior geographical location and convenient transportation provide convenient conditions for contact and cooperation between the two locations. In 2017, Baoding's GDP (306.8 billion yuan) and land price (3264 yuan per $\mathrm{m}^{2}$ ) were lower than those of Shijiazhuang (592.7 billion yuan and 3954 yuan per $\mathrm{m}^{2}$ ). However, from 2014 to 2017, Baoding's GDP growth rate $(31.9 \%)$ and land-price growth rate $(21.7 \%)$ were higher than those of Shijiazhuang $(16.3 \%$ and $18.6 \%$, respectively). In the process of the coordinated development of the Beijing-Tianjin-Hebei region, influenced by Beijing and Tianjin, Baoding's social and economic development and land-market changes are strongly influenced by Beijing and Tianjin, and it has become an important radiation city in relation to Beijing, helping to guide the development of Shijiazhuang. In turn, Shijiazhuang has played an important role in radiating and guiding the development of southern cities in the region, especially Hengshui. The interaction distance between Shijiazhuang and Hengshui is $145 \mathrm{~km}$, and the gravitational attraction value is 1.43 . As the city with the greatest economic strength and the most convenient transportation system of all the cities around Hengshui, Shijiazhuang should become the largest gravitational city of Hengshui. Tangshan is the largest gravitational city of Qinhuangdao, and is a transportation hub for Qinhuangdao's external economic connection. The interaction distance between Tangshan and Qinhuangdao is $141 \mathrm{~km}$, and the gravitational attraction value is 1.16. Qinhuangdao is adjacent to Tangshan and Chengde, and regardless of the economy and culture, is more closely connected with Tangshan, which has become an important city in terms of transmitting Beijing-Tianjin radiation and guiding the development of Qinhuangdao.

\subsubsection{Convection Land Price}

The convection pattern occurs when two adjacent cities are the most attractive cities in terms of each other's land price. In general, convective cities are far from the center of urban agglomeration, and have the same spatial status. Handan and Xingtai are in the southernmost part of the region, and being affected by accessibility factors, they are more closely related to each other and, thus, have become convective cities. Xingtai is adjacent to Shijiazhuang and Hengshui in the north and Handan in the south. The interaction distances between Xingtai and Shijiazhuang, Hengshui, and Handan are $124 \mathrm{~km}, 178 \mathrm{~km}$, and $62 \mathrm{~km}$, respectively, and the land-price gravity values are 1.95, 0.09, and 4.16, respectively. It can be seen that travel between Xingtai and Handan is more convenient and, thus, the attraction of land prices is greater. In terms of external relations, Xingtai and Handan have Chenjiao Airport and Matou Airport, respectively, which basically meet the needs of their air travel, thus weakening the demand for Shijiazhuang Airport. In terms of economic development, Xingtai and Handan are focusing on the iron and steel, coal, and building materials industries. The industrial structure, industrial policy, and land-use policy of the two places have convergence. From 2014 to 2017, the growth rates of land prices in Shijiazhuang, Hengshui, Xingtai, and Handan were 18.6\%, 
$10.1 \%, 31.4 \%$, and $120.3 \%$, respectively. It can be seen that the changes in land prices in Xingtai and Handan are most relevant, and the rapid growth of land prices in Handan has had a significant impact on Xingtai. The convenience of transportation, the similarity of industrial structures, and the correlation of land price changes all reflect the strong interaction between Xingtai and Handan, forming a convective city relationship. However, these two cities are distant from the regional center, with relatively weak links with other cities and receiving relatively less radiation from central cities, resulting in the isolation phenomenon.

In general, the Beijing-Tianjin-Hebei urban land-price level shows a polarized pattern of development centered on Beijing and Tianjin. Hebei Province shows a development trend with Shijiazhuang, Baoding, Tangshan, and Qinhuangdao as secondary centers. The central and northern cities of the region are closely linked, while Handan and Xingtai in the southern area of the region form a "club" of cities with each other. Based on the strongest gravitational connection lines for land prices among cities, four gravitational corridors of land prices have been formed: Zhangjiakou-Beijing-Tianjin, Chengde-Beijing-Baoding-Shijiazhuang, Cangzhou-TianjinTangshan-Qinhuangdao, and Shijiazhuang-Hengshui, which roughly form two gravitational chains of land prices in an east-west direction and two gravitational chains of land prices in a north-south direction, resulting in a "\#-shaped" gravitational pattern of land prices (see Figure 8).

\subsection{Characteristics of Gravitational Patterns of Urban Land Prices}

\subsubsection{Polarization Effect around Beijing and Tianjin}

Based on the border signifying the gravitational equilibrium of land prices, the ratio of the sum of the gravitational attraction of land prices of each urban cluster to the total gravitational attraction of regional urban land prices reflects the interaction intensity of the land price of each urban group and the overall distribution pattern of the gravitational attraction of land prices in the Beijing-Tianjin-Hebei region. The total land-price gravity in the Beijing-Tianjin-Hebei urban agglomeration is 185.73, and that of the city cluster around Beijing is 123.39 , accounting for $66.4 \%$ of the total. The total gravitational value of land prices in the central coastal city cluster is 46.36 , accounting for $25.0 \%$ of the total. The total gravitational values of the central city cluster, the southern city cluster, and the northern coastal city cluster are $9.23,4.16$, and 2.59 , respectively, accounting for $5.0 \%, 2.2 \%$, and $1.4 \%$ of the total, respectively. The total land-price gravity of the city cluster around Beijing is nearly twice that of the sum of the other groups and 47.6 times that of the northern coastal city cluster. Thus, there is a polarization effect in relation to the land-price gravity pattern in the Beijing-Tianjin-Hebei urban agglomeration. In 2017, Beijing's per capita GDP, population density, and investment in fixed assets reached 2.86, 3.34, and 0.77 times those of the cities in Hebei Province, respectively, while in Tianjin, they reached 2.64, 3.32, and 0.51 times those of the cities in Hebei Province, respectively. Thus, the economic level of the cities in the Beijing-Tianjin-Hebei region is unbalanced, and the pattern is similar to the gravitational structure of land prices. It can be seen that after years of development and accumulation, Beijing and Tianjin have produced good economies of scale and achieved external competitiveness in terms of economic development. Beijing's economic strength and price attractiveness are significant. Hebei Province surrounds Beijing and Tianjin, and shoulders the heavy burden of controlling the hazard presented by sand storms, reforesting formerly cultivated land, and developing ecological conservation areas. The government's policies of restricting land resource development and industrial production have restricted the economic development of relevant areas in Hebei to some extent. The separation of ecological protection and economic development policies in the Beijing-Tianjin-Hebei region has led Hebei Province to focus on environmental protection and limit the development and utilization of land resources, while the development of the land market is obviously focused on Beijing and Tianjin. 


\subsubsection{Lock-In Effect in Southern Hebei}

The gravitational pattern of urban land prices in the Beijing-Tianjin-Hebei region has a typical lock-in feature, which is mainly reflected in the cities around Beijing and Southern Hebei, resulting in unbalanced regional development. Beijing, Tianjin, and Langfang have accumulated large volumes of high-quality human and material resources with the support of their superior geographical location and policies. With the development of the economy, the three cities have realized their complementary advantages through the optimal allocation of resources and, thus, achieved a high level of land-price gravitation. The southern part of Hebei Province is at a disadvantage in terms of location and is basically in a marginal zone affected by the land prices in Beijing and Tianjin. For example, Xingtai and Handan are gravitational convection cities with land-price qualities of 6.03 and 8.62, respectively. The transportation accessibility coefficient between Xingtai and Handan and Beijing is only 0.66 and 0.62 , respectively, and the transportation accessibility coefficient between Xingtai and Handan and most other cities in the region is less than 1. Due to the low level of transportation accessibility and the low level of the land market, Xingtai and Handan have formed a locally locked pattern. This lock-in effect is likely to lead to increasing differences in relation to regional development that will be difficult to change in the short term, thereby restricting the coordinated development of the Beijing-Tianjin-Hebei region.

\subsection{Suggestions Regarding Land-Price Control Measures in The Beijing-Tianjin-Hebei Region}

The level of urban land prices affects the rationality of land values, as well as economic and social development. The coordination of land prices in the various cities in the region affects the coordination of the economic and social development of those cities, and also affects the optimal allocation of land resources in the region. Therefore, how to effectively balance urban land prices in the region is particularly important. The polarization effect and partial lock-in effect of land prices in the Beijing-Tianjin-Hebei urban agglomeration reflect the imbalance in land-market development between cities, which directly affects the coordinated development of the region. Thus, we put forward several suggestions regarding regional land-price regulatory measures. First, we should alleviate the non-capital core functions of Beijing, make full use of the advantages of land resources in each city to alleviate the development pressure on Beijing and Tianjin, and improve the comprehensive strength of other cities, especially marginal cities, thereby weakening the polarization effect on urban land prices and the level of land market development in the region. Langfang, Baoding, Zhangjiakou, and Chengde surround Beijing and Tianjin, forming a gravitational urban cluster with Beijing. We suggest that these four cities should take the lead in absorbing the industries transferred from Beijing and Tianjin, relying on their geographical advantages and existing industrial base to gradually ease the pressure on Beijing and Tianjin. In the process of this industrial transfer, the urban cluster around Beijing and Tianjin must overcome the barriers presented by administrative divisions and formulate unified land-use planning and land-trading policies, such as jointly formulating an annual land-supply plan and establishing a land-auction platform. These practices will contribute to the balanced development of the land market around Beijing and Tianjin. The government should formulate a unified land-use policy, and synchronize industrial transfers and land supply to avoid wastage of land caused by industrial transfers occurring faster than the supply of suitable land. The monitoring system for land prices in the cities surrounding Beijing and Tianjin should be improved, including the establishment of unified land-price valuation standards, such as unified standard of land volume fraction and development degree, to enable the comparison and balancing of land prices between cities.

Second, the regional traffic network and economic cooperation among cities should be enhanced, including the cultivation of new central cities in Beijing, Tianjin, and Hebei to facilitate a transformation from a single-center radial traffic system to a multi-center networked traffic system. Meanwhile, Beijing and Tianjin should increase their economic links and radiation to other cities (especially Handan, Xingtai, Hengshui, and other southern cities) to alleviate the locked-in effect of urban development in the south. Based on the existing traffic pattern, linking the trunk railway with the inter-city railway, enhancing the construction of transport node facilities, such as passenger transport hubs and freight 
transport hubs, and forming an efficient and dense traffic network will improve traffic accessibility and economic links between cities. For example, in the coastal city cluster, the Beijing-Shanghai high-speed railway should be completed as soon as possible, and the urban transportation systems of Tianjin, Tangshan, and Cangzhou should be improved to help them absorb the industrial projects transferred from Beijing and form a coastal industrial belt. The construction of expressways in the southern city cluster, such as the Beijing-Guangzhou high-speed railway and the Beijing-Kowloon high-speed railway should be accelerated, and the urban transport systems between Beijing and Xingtai, Handan, and Hengshui should be upgraded so that these three cities can provide more cheap land and labor resources for Beijing and Tianjin. These measures will help to strengthen the social and economic links between southern cities and Beijing, thereby helping to overcome the current closed development of the southern cities.

Third, the radiation-driving capacity of Shijiazhuang, Baoding, and Tangshan, three cities performing a land price conduction function, needs to be strengthened to gradually form a closely related networked spatial structure. Based on the policies relating to the adjustment of the industrial structure of various cities, it is important to facilitate the orderly transfer of industries, promote the free flow of land-market elements, and promote the coordinated development of the entire regional land market. Shijiazhuang is the central city in the central city cluster, Tangshan is the central city in the northern coastal city cluster, and Baoding is an important development city node in the Beijing-centered city cluster. Thus, these three cities play important roles in the coordinated development of Beijing, Tianjin, and Hebei, and the government should work hard to enhance the economic strength of these three cities so that they can become secondary radiation centers for regional development. For example, the government should strengthen the support provided to these three cities and further improve their urban public infrastructure and transportation facilities. This will enhance their agglomeration effect in areas such as science, technology, talent, finance, and capital, thereby enhancing their comprehensive strength and land values, and improving their radiation capacity in relation to low-cost cities such as Hengshui, Xingtai, and Cangzhou. The government should formulate a realistic land-price regulation policy, construct a reasonable land-price gradient, and avoid malicious competition among cities. These measures will assist the rational, timely transfer of industries from Beijing and Tianjin.

\section{Conclusions}

The purpose of this study is to understand the land-price levels in the Beijing-Tianjin-Hebei urban agglomeration and the interactions between various related factors reveal the characteristics of regional land-price interaction patterns, and identify the appropriate direction for the coordinated development of the regional land market in the future. To eliminate the influence of policy interventions on land-price levels and objectively reflect the real levels of urban land prices and the degree of development of the land-market economy, we use influencing factors that are closely related to urban land prices and use a comprehensive index evaluation method to measure the quality of land prices. The land-price gravity among cities is calculated using the gravity model, and the intensity and types of interactions among urban land prices in the region are obtained. Using a Voronoi diagram model based on breaking-point theory, the gravitational patterns in relation to urban land prices are identified and the characteristics of the regional gravitational patterns in land prices are revealed. An analysis of gravitational intensity and pattern characteristics reveals that there are some problems in the Beijing-Tianjin-Hebei region, such as unbalanced urban land-price levels, unbalanced interconnections, an obvious polarization effect, and a local lock-in effect. Based on these findings, we propose several countermeasures.

Based on the results of our analysis, we conclude that: (1) The intensity and scope of the interactions between urban land prices are positively correlated with the quality of the land prices and the degree of accessibility between cities, and the quality and distance of urban land prices are important parameters for analyzing the relationship between urban land prices; (2) there are significant differences in the gravitational intensity of urban land prices in the region. The gravitational force of Beijing, Tianjin, and Langfang is much higher than that of other cities, while the gravitational force of other cities 
in Hebei Province is obviously weak. The gravity of land prices in the Beijing-Tianjin-Hebei urban agglomeration shows the spatial differentiation characteristics of "More cities with weak gravity and fewer cities with strong gravity, with the cities around Beijing and Tianjin closely connected, while the peripheral cities are loosely connected."; (3) based on the distribution of the strongest gravitational connection lines between cities, it is found that the area has formed a "\#-shaped" pattern of land-price interactions consisting of two horizontal and two vertical belts. Using the heat transfer model involving the processes of convection, radiation, and conduction, it is concluded that Beijing is a land-price radiation city, Shijiazhuang, Baoding, and Tangshan are land-price conduction cities, and Handan and Xingtai are land-price convection cities; (4) the scope of influence of land prices in each city has extended beyond the original administrative boundaries, and can be divided into five clusters based on the gravitational relationships among land prices, namely, the city cluster around Beijing, the northern coastal city cluster, the central coastal city cluster, the central city cluster, and the southern city cluster; and (5) based on the gravitational characteristics of land prices among cities and the overall gravitational distribution of land prices in the five urban clusters, it is found that the polarization effect of urban land prices in the Beijing-Tianjin-Hebei region is clearly evident, as is the lock-in effect in southern cities. Based on these findings, we put forward three measures and suggestions to promote balanced land prices and the coordinated development of the land-market economy in the region, namely, alleviating the non-capital core functions of Beijing, strengthening the transportation network in the region, and enhancing the role of land-price transmission cities such as Shijiazhuang, Baoding, and Tangshan. Government departments should implement an integrated development strategy based on the overall functional orientation of the Beijing-Tianjin-Hebei region, as well as the development basis and potential of each city, so that the region can embark on a truly coordinated development path.

Author Contributions: Conceptualization: C.L. and J.G.; methodology: all; validation: Y.M.; formal analysis: C.L. and C.Z.; investigation: C.Z.; resources: Y.M.; data curation: all; writing-original draft preparation: C.L.; writing-review and editing: Y.L. and J.G.; visualization: C.L.

Funding: The writing of the paper was supported by the Chinese National Science Foundation (project no. 41471090) and Hebei Province National Science Foundation (project no. D2015205225).

Acknowledgments: The authors would like to thank the anonymous reviewers and handling editors for their constructive comments that greatly improved this article from its original form. We thank Geoff Whyte, MBA, from Liwen Bianji, Edanz Group China (www.liwenbianji.cn/ac), for editing the English text of a draft of this manuscript.

Conflicts of Interest: The authors declare no conflict of interest.

\section{References}

1. Siciliano, G. Urbanization strategies, rural development and land use changes in China: A multiple-level integrated assessment. Land Use Policy 2012, 29, 165-178. [CrossRef]

2. Yang, X.J. China's rapid urbanization. Science 2013, 342, 310. [CrossRef] [PubMed]

3. Long, H. Land use policy in China: Introduction. Land Use Policy 2014, 40, 1-5. [CrossRef]

4. Chen, M.; Liu, W.; Lu, D. Challenges and the way forward in China's new-type urbanization. Land Use Policy 2016, 55, 334-339. [CrossRef]

5. Yang, K. The change of regional industrial structure and its effect on the regional growth and specialization in China. Acta Geogr. Sin. 1993, 48, 481-490.

6. Burnett, P. Land use regulations and regional economic development. Land Econ. 2016, 92, $237-255$. [CrossRef]

7. Xu, S. The 13th Five-Year Plan for National Economic and Social Development of the People Republic of China (2016-2020); Compilation \& Translation Press: Beijing, China, 2016.

8. Chen, M.; Guo, S.; Lu, D. Characteristics and spatial patterns of floating population in the Beijing-Tianjin-Hebei urban agglomeration under the background of new urbanization. Prog. Geogr. 2018, 37, 363-372.

9. Tan, M.; Li, X.; Xie, H.; Lu, C. Urban land expansion and arable land loss in China-A case study of Beijing-Tianjin-Hebei region. Land Use Policy 2005, 22, 187-196. [CrossRef]

10. Wang, S.; Ma, H.; Zha, Y. Exploring the relationship between urbanization and the eco-environment-A case study of Beijing-Tianjin-Hebei region. Ecol. Indic. 2014, 45, 171-183. [CrossRef] 
11. Chen, X.; Liu, Y.; Lu, H.; Hu, X. Spatial identification of multifunctional landscapes and associated influencing factors in the Beijing-Tianjin-Hebei region, China. Appl. Geogr. 2016, 74, 170-181.

12. el Araby, M.M. The role of the state in managing urban land supply and prices in Egypt. Habitat Int. 2003, 27, 429-458. [CrossRef]

13. Yang, K.; Wang, Y.; Zhang, S. City land price factorial analysis and spatial distribution research in Jiangsu province. Hum. Geogr. 2013, 1, 69-74.

14. Yang, S.; Hu, S.; Li, W.; Zhang, C.; Torres, A.J. Spatiotemporal Effects of Main Impact Factors on Residential Land Price in Major Cities of China. Sustainability 2017, 9, 2050. [CrossRef]

15. Nasr, K.; Boris, A.P. Economic, demographic and environmental factors affecting urban land prices in the Arab sector in Israel. Land Use Policy 2016, 50, 518-527.

16. Hu, S.; Yang, S.; Li, W.; Zhang, C.; Xu, F. Spatially non-stationary relationships between urban residential land price and impact factors in Wuhan city, China. Appl. Geogr. 2016, 68, 48-56. [CrossRef]

17. Liu, Y.; Zheng, B.; Turkstrae, J.; Huan, L. A hedonic model comparison for residential land value analysis. Int. J. Appl. Earth Obs. Geoinf. 2010, 12, S181-S193. [CrossRef]

18. Huang, D.; Yang, X.; Liu, Z.; Zhao, X.; Kong, F. The Dynamic Impacts of Employment Subcenters on Residential Land Price in Transitional China: An Examination of the Beijing Metropolitan Area. Sustainability 2018, 10, 1016. [CrossRef]

19. Glaesener, M.-L.; Caruso, G. Neighborhood green and services diversity effects on land prices: Evidence from a multilevel hedonic analysis in Luxembourg. Landsc. Urban Plan. 2015, 143, 100-111. [CrossRef]

20. Zhu, J.; Chen, B.; Lu, P.; Liu, J.; Tang, G. Impact of urban water system treatment on the surrounding residential land price. Arab. J. Geosci. 2018, 11, 6. [CrossRef]

21. Cervero, R.; Kang, C.D. Bus rapid transit impacts on land uses and land values in Seoul, Korea. Transp. Policy 2011, 18, 102-116. [CrossRef]

22. Shen, Y.; Karimi, K. The economic value of streets: Mix-scale spatio-functional interaction and housing price patterns. Appl. Geogr. 2017, 79, 187-202. [CrossRef]

23. Lee, J.; Sohn, K. Identifying the Impact on Land Prices of Replacing At-grade or Elevated Railways with Underground Subways in the Seoul Metropolitan Area. Urban Stud. 2014, 51, 44-62. [CrossRef]

24. Du, J.; Richard, B.P. Land supply, pricing and local governments' land hoarding in China. Reg. Sci. Urban Econ. 2014, 48, 180-189. [CrossRef]

25. Kok, N.; Monkkonen, P.; Quigley, M. Land use regulations and the value of land and housing: An intra-metropolitan analysis. J. Urban Econ. 2014, 81, 136-148. [CrossRef]

26. Davis-Regional, M.A. The price and quantity of land by legal form of organization in the United States. Sci. Urban Econ. 2009, 39, 350-359. [CrossRef]

27. Du, H.; Yong, K.; An, M.Y. The impact of land policy on the relation between housing and land prices: Evidence from China. Q. Rev. Econ. Financ. 2011, 51, 19-27. [CrossRef]

28. Ridker, R.G.; Henning, J.A. The determinants of residential property values with special reference to air pollution. Rev. Econ. Stat. 1967, 49, 246-257. [CrossRef]

29. Freeman, A.M. The Measurement of Environmental and Resource Values: Theory and Methods; University of Wisconsin Press: Madison, WI, USA, 1996; pp. 274-275.

30. Brasington, D.M.; Diane, H. Demand for environmental quality: A spatial hedonic analysis. Reg. Sci. Urban Econ. 2005, 35, 57-82. [CrossRef]

31. Bastian, C.T.; McLeod, M.D.; Germino, M.J.; Reiners, M.A.; Benedict, J.B. Environmental amenities and agricultural land values: A hedonic model using geographic information systems data. Ecol. Econ. 2002, 40, 337-346. [CrossRef]

32. Kim, S.; Kim, T.; Suh, K. Analysis of the Implication of Accessibility to Community Facilities for Land Price in Rural Areas using a Hedonic Land Price Model. J. Korean Soc. Rural Plan. 2016, 22, 93-100. [CrossRef]

33. Jim, C.Y.; Chen, Y. Impacts of urban environmental elements on residential housing prices in Guangzhou (China). Landsc. Urban Plan. 2006, 78, 422-434. [CrossRef]

34. Sander, H.A.; Stephen, P. The value of views and open space: Estimates from a hedonic pricing model for Ramsey County, Minnesota, USA. Land Use Policy 2009, 26, 837-845. [CrossRef]

35. Sander, H.A.; Haight, R.G. Estimating the economic value of cultural ecosystem services in an urbanizing area using hedonic pricing. J. Environ. Manag. 2012, 113, 194-205. [CrossRef] [PubMed] 
36. Huang, H.; Yin, L. Creating sustainable urban built environments: An application of hedonic house price models in Wuhan, China. J. Hous. Built Environ. 2015, 30, 219-235. [CrossRef]

37. Glumac, B.; Herrera-Gomez, M.; Lichero, J. A hedonic urban land price index. Land Use Policy 2019, 81, 802-812. [CrossRef]

38. Song, J.; Jin, X.; Tang, J.; Zhang, Z.; Ding, N.; Zhao, J.; Zhou, Y. Analysis of Influencing Factors for Urban Land Price and Its Changing Trend in China in Recent Years. Acta Geogr. Sin. 2011, 66, 1045-1054.

39. Han, J.; Jin, X.; Zhang, Z.; Sun, W.; Xu, X.; Zhou, Y. Development Characteristics and Factors Analysis of Residential Land Price in China. Sci. Geogr. Sin. 2017, 37, 573-584.

40. Coomeas, O.T.; MacDonald, K.G.; le Polain de Waroux, Y. Geospatial Land Price Data: A Public Good for Global Change Science and Policy. BioScience 2018, 68, 481-484. [CrossRef]

41. Qin, Y.; Zhu, H.; Zhu, R. Changes in the distribution of land prices in urban China during 2007-2012. Reg. Sci. Urban Econ. 2016, 57, 77-90. [CrossRef]

42. Hu, S.; Cheng, Q.; Wang, L.; Xie, S. Multifractal characterization of urban residential land price in space and time. Appl. Geogr. 2012, 34, 161-170. [CrossRef]

43. Goffette-Nagot, F.; Reginster, I.; Thomas, I. Spatial analysis of residential land prices in Belgium: Accessibility, linguistic border, and environmental amenities. Reg. Stud. 2011, 45, 1253-1268. [CrossRef]

44. Davis, M.A.; Oliner, S.D.; Pinto, E.J.; Bokka, S. Residential land values in the Washington, DC metro area: New insights from big data. Reg. Sci. Urban Econ. 2017, 66, 224-246. [CrossRef]

45. Hu, S.; Cheng, Q.; Wang, L.; Xu, D. Modeling land price distribution using multifractal IDW interpolation and fractal filtering method. Landsc. Urban Plan. 2013, 110, 25-35. [CrossRef]

46. Wen, H.; Chu, L. The Analysis on Spatial-Temporal Evolution and Impacting Factors of Residential Land Price in Hangzhou: Evidence Based on Spatial Econometric Model. In Proceedings of the 7th International Conference on Education, Management, Computer and Medicine (EMCM 2016), Shenyang, China, 29-31 December 2017.

47. Wen, H.; Goodman, A.C. Relationship between urban land price and housing price: Evidence from 21 provincial capitals in China. Habitat Int. 2013, 40, 9-17. [CrossRef]

48. Zou, G.; Chau, K. Determinants and sustainability of house prices: The case of Shanghai, China. Sustainability 2015, 7, 4524-4548. [CrossRef]

49. Huang, H.; Tang, Y. Residential land use regulation and the US housing price cycle between 2000 and 2009. J. Urban Econ. 2012, 71, 93-99. [CrossRef]

50. Chen, W.; Shen, Y.; Wang, Y. Does industrial land price lead to industrial diffusion in China? An empirical study from a spatial perspective. Sustain. Cities Soc. 2018, 40, 307-316. [CrossRef]

51. Ding, C.; Zhao, X. Land market, land development and urban spatial structure in Beijing. Land Use Policy 2014, 40, 83-90. [CrossRef]

52. Du, J.; Thill, J.C.; Peiser, R.B. Land pricing and its impact on land use efficiency in post-land-reform China: A case study of Beijing. Cities 2016, 50,68-74. [CrossRef]

53. Liu, Z.; Wang, P.; Zha, T. Land-price dynamics and macroeconomic fluctuations. Econometrica 2013, 81, 1147-1184.

54. Liu, T.; Huang, M. Land supply and money growth in China. Int. Rev. Econ. Financ. 2016, 42, 327-338. [CrossRef]

55. Du, J.; Thill, J.C.; Peiser, R.B.; Feng, C. Urban land market and land-use changes in post-reform China: A case study of Beijing. Landsc. Urban Plan. 2014, 124, 118-128. [CrossRef]

56. Wu, Y.; Zhang, X.; Skitmore, M.; Song, Y.; Hui, E.C.M. Industrial land price and its impact on urban growth: A Chinese case study. Land Use Policy 2014, 36, 199-209. [CrossRef]

57. Zhang, X.; Lin, Y.; Wu, Y.; Skitmore, M. Industrial land price between China's Pearl River Delta and Southeast Asian regions: Competition or Coopetition? Land Use Policy 2017, 61, 575-586. [CrossRef]

58. Anderson, J.E. The Gravity Model. Annu. Rev. Econ. 2011, 3, 133-160. [CrossRef]

59. Reilly, W.J. Methods for the Study of retail relationships. Univ. Tex. Bull. 1929, 44, 1-9.

60. Zipf, G.K. Hypothesis: On the Intercity Movement of Persons. Am. Sociol. Rev. 1946, 11, 677-686. [CrossRef]

61. Çağdaş, G.; Berk, L. Dynamic Behavior of the City Center in Istanbul. Comput. Environ. Urban Syst. 1996, 20, 153-164. [CrossRef]

62. Matsumoto, H. International Urban Systems and Air Passenger and Cargo Flows: Some Calculations. J. Air Transp. 2004, 10, 239-247. [CrossRef] 
63. Fotheringham, A.S. A new set of spatial interaction models. Environ. Plan. A 1983, 15, 15-36. [CrossRef]

64. Celik, H.M.; Guldmann, J.M. Spatial interaction modeling of interregional commodity flows. Socio-Econ. Plan. Sci. 2007, 41, 147-162. [CrossRef]

65. Djankov, S.; Freund, C. Trade Flows in the Former Soviet Union, 1987 to 1996. J. Comp. Econ. 2002, 30, 76-90. [CrossRef]

66. Russon, M.G.; Vakil, F. Population, convenience and distance decay in a short-haul model of United States air transportation. J. Transp. Geogr. 1995, 3, 179-185. [CrossRef]

67. Vaz, E.; Nijkamp, P. Gravitational forces in the spatial impacts of urban sprawl: An investigation of the region of Veneto, Italy. Habitat Int. 2015, 45, 99-105. [CrossRef]

68. Lin, J.; Li, X. Simulating urban growth in a metropolitan area based on weighted urban flows by using web search engine. Int. J. Geogr. Inf. Sci. 2015, 29, 1721-1736. [CrossRef]

69. Escamilla, J.B.G.; Pérez, S.L.; Martínez, Y.R.; Mendoza, S. Gravitational Model to Predict the Megalopolis Mobility of the Center of Mexico. Int. J. Adv. Eng. Manag. Sci. 2018, 4, 10. [CrossRef]

70. He, C.; Zhao, Y.; Tian, J.; Shi, P. Modeling the urban landscape dynamics in a megalopolitan cluster area by incorporating a gravitational field model with cellular automata. Landsc. Urban Plan. 2013, 113, 78-89. [CrossRef]

71. Scherngell, T.; Hu, Y. Collaborative knowledge production in China: Regional evidence from a gravity model approach. Reg. Stud. 2008, 45, 755-772. [CrossRef]

72. Qian, C.; Ye, J.; Lu, C. Gravity zoning in Wuhan Metropolitan Area based on an improved urban gravity model. Prog. Geogr. 2015, 34, 237-245.

73. Zhu, D.; Lu, L.; Jin, X. Spatial Patterns of City in Anhui Province Based on Gravity Model. Geogr. Sci. 2011, 31, 551-556.

74. Lao, X.; Shen, T.; Yang, Y. A Study on the Economic Network of the Urban Agglomeration in the Middle Reaches of the Yangtze River: Based on Social Network Analysis Method with Gravity Model. Urban Dev. Stud. 2016, 23, 91-98.

75. Zhao, Z.; Wang, J.; Feng, J. Research on the Spatial Correlation of Central Cities in Beijing-Tianjin-Hebei. Urban Agglom. Econ. 2017, 37, 60-66.

76. Xu, Y.; Zhou, Y.; Xu, F. Regional Effection Model Attributed to Revise Standard Price of Urban Land Spatially. Econ. Geogr. 2003, 3, 355-358.

77. Liu, Y.; Liu, Y.; Lan, Z.; Xia, Y.; Liu, W. Balance of Datum Land Prices Among Cities Based on the City Gravitation Model and Stochastic Diffusion Equation. Geo-Spat. Inf. Sci. 2008, 11, 71-78. [CrossRef]

78. Zhao, L.; Ge, J. Urban Land Price Based on the Gravity Model: A Case Study of Jing-Jin-Ji Metropolitan Region. China Land Sci. 2013, 27, 53-58.

79. Liang, Y.; Cai, X.; Zhang, L. The study about influence differences and extremum attenuation degree of regional urban land price. J. Arid Land Resour. Environ. 2018, 32, 49-57.

80. Liu, M.; Wang, W.; Liu, J. The Delimitation and Evolution Pattern of Cities Space Attractive Scopes in the Zhongyuan Urban Agglomeration. Reg. Res. Dev. 2017, 36, 49-54.

81. Liu, A.; Xie, Z. Division of Town Economic Zones Based on Weighted Voronoi Diagram: A Case Study of Shiyan. Geogr. Geogr. Inf. Sci. 2011, 27, 79-82.

82. Wei, X.; Liang, J.; Hou, H. Delimitating town's field based on analysis of road network voronoi diagram: A case study of Daye city. Geogr. Geogr. Inf. Sci. 2014, 30, 66-70.

83. Guo, X.; Li, Y.; Ma, L. Research on Structure of Urban System Based on the Model of Improved Converse Breaking Point and Weighted Voronoi Diagram: A Case Study of Tianshui. Reg. Res. Dev. 2017, 36, 70-75.

84. Song, Z.; Xiao, J. Analysis on the Land Price Factors in the Context of Macro-level Framework. China Land Sci. 2012, 26, 4-11.

85. Li, C.; Liu, C.; Ge, J.; Liang, S.; Liu, J. The rationality of the land price in different grades of towns: Taking Hebei province as an example. J. Arid Land Resour. Environ. 2017, 31, 51-58.

86. Ministry of Natural Resources of the Peple's Republic of China; Chinese Land Surveying and Planning Institute. Regulations for Valuations on Urban Land (GB/T 18508-2014); Standards Press of China: Beijing, China, 2014.

87. Guo, P.; Xu, R. The Relationship between Urban Rail Transit and Urban Development Based on Gravitation Field Model. Syst. Eng. 2006, 24, 36-40. 
88. Liu, Y. Assessment Model and Spatial Distribution Features of Urban Land Value in China. China Popul. Resour. Environ. 1998, 1, 20-25.

89. Zheng, G.; Zhao, Q. Research on the Main Direction of Economic Contact of Shandong Peninsula City Agglomeration. Areal Res. Dev. 2004, 23, 51-54.

90. Yang, S.; Zhang, L.; Yang, C.; Liu, T.-T. Highway route scheme optimization model based on identical degree of set pair analysis. J. Transp. Syst. Eng. Inf. Technol. 2008, 8, 115-119.

91. He, M.; Liu, L.; Wang, H.; Liu, J. Unknown weight multiple attribute decision for engineering appraisal bidding based on set pair analysis. J. Cent. South Univ. 2012, 43, 4057-4062.

92. Liu, C.; Yu, R.; Xiong, J.; Zhu, J.-L.; Zhang, H. The spatial structure of economic linkage of Wuhan metropolitan area. Geogr. Res. 2007, 26, 197-208.

93. Zhang, X.; Guo, H.; Zhang, H. Fractal Characteristic of Regional Economic Relation Intensity and It's Application in Western China. Acta Sci. Nat. Univ. Pekin. 2007, 43, 245-249.

94. Okabe, A.; Boots, B.; Sugihara, K. Spatial Tessellations: Concepts and Applications of Voronoi Diagrams; John Wiley \& Sons: Hoboken, NJ, USA, 2000; pp. 15-20.

95. Gu, J.; Zhou, T.; Guo, L. Urban Influence Regions and Spatial Relation of Beijing-Tianjin-Hebei Region Based on Weighted Voronoi Diagram and Breakpoint Theory. Geogr. Geo-Inf. Sci. 2014, 30, 65-69.

(C) 2019 by the authors. Licensee MDPI, Basel, Switzerland. This article is an open access article distributed under the terms and conditions of the Creative Commons Attribution (CC BY) license (http://creativecommons.org/licenses/by/4.0/). 